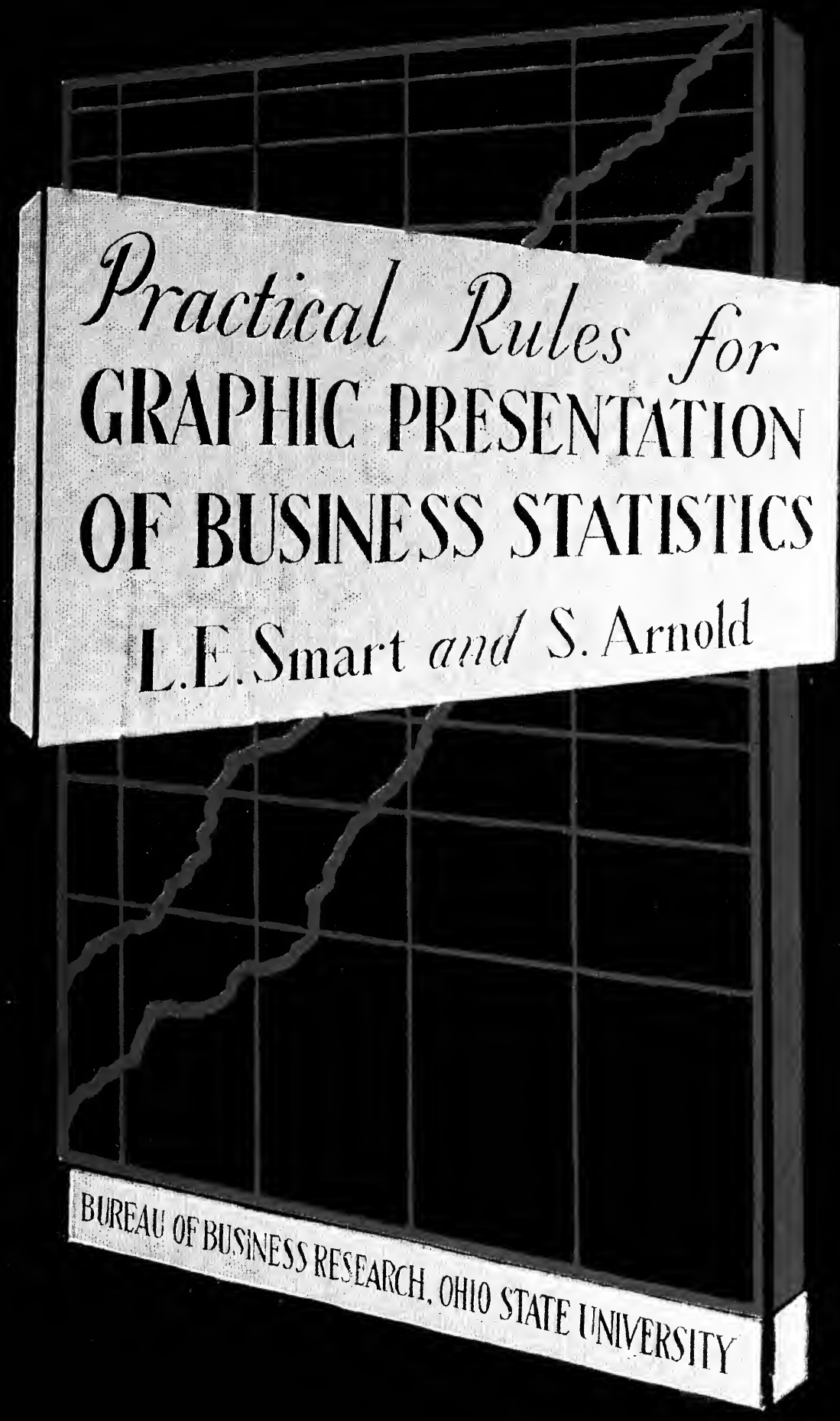



- 
PRACTICAL RULES FOR GRAPHIC PRESENTATION OF BUSINESS STATISTICS 


\section{-}

. 


\title{
PRACTICAL RULES FOR GRAPHIC PRESENTATION OF BUSINESS STATISTICS
}

\author{
By \\ L. Edwin SMart, Ph.D. \\ Professor of Economics, Ohio State University \\ and \\ Sam Arnold, Ph.D. \\ Assistant Professor, Ohio State University
}

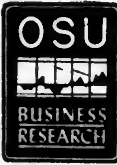

Published By

The Bureau of Business Research COLLEGE OF COMMERCE AND ADMINISTRATION THE OHIO STATE UNIVERSITY

COLUMBUS, OHIO 


\title{
COLLEGE OF COMMERCE AND ADMINISTRATION \\ Walter C. Weidler, Dean
}

\author{
BUREAU OF BUSINESS RESEARCH STAFF \\ Viva Boothe, Director \\ SAM Arnold, Economics \\ Mikhail V. Condoide, Research Associate \\ James C. Yocum, Marketing \\ Helen P. Zwick, Secretary \\ Barbara A. Lynn, Research Assistant \\ Joan P. Whipple, Research Assistant \\ Emma Ferrin, Research Assistant
}




\section{PREFACE}

The aim of this publication is to present in a clear and concise manner the essential rules for correct construction of the most widely-used types of business charts.

The rules are set forth in outline form with textual discussion reduced to a minimum. One or more charts illustrating the applications of the rules are provided in conjunction with the outline material for each of the various types of charts.

The manual does not attempt to give alternative practices, but offers complete and easily followed basic instructions for making charts in accordance with generally accepted standards.

Viva Boothe, Director 


\section{FOREWORD}

The problem of effectively presenting business statistical data in graphic form has perplexed many accountants as well as statisticians, particularly the highly-trained mathematical statisticians. No matter how much imaginative genius or artistic talent is reflected in a chart, it can never be effective unless it is clear and forcefulclear in the sense that the reader has the information necessary to evaluate the data charted, and forceful in the sense that the most significant data are plotted. The "beauty" in a business chart does not lie in its artistic flourishes but in the business-economic meaning and implications which the chart clearly conveys. That is to say, the beauty does not necessarily meet the eye but inheres rather in the quality of the reasoning in which the chart plays its part.

Effectiveness-clarity and forcefulness-is best obtained by presenting all the pertinent facts in such a way that the chart, in and by itself, is a complete entity with proper relationships being maintained in the chart in order that the most important data be given most emphasis and the subordinate information be given less emphasis.

It is important to be constantly concerned that integrity be preserved in all charts. Charts can be drawn so as to create optical illusions or to create erroneous impressions which may lead the reader to unwarranted conclusions. Such practices, whether premeditated or accidental, should be avoided.

This monograph sets forth, with illustrations, the general rules and principles which should be followed in order that business data may be presented most effectively and with integrity by graphic means, and as such will be most useful in serving as a reference guide. The intent was not to give the pros and cons of various practices for making graphs or to present the variants in practice which might be used.

The writers acknowledge their debt to the many persons whose formal work has enriched the field of graphic presentation, and to their colleagues at The Ohio State University, particularly to Professors Viva Boothe, Mary Louise Mark, and James C. Yocum. Sincere appreciation is also extended Virginia Klinkman for her painstaking draftsmanship. 


\section{CONTENTS}

Preface................................................. Page

Foreword $\ldots \ldots \ldots \ldots \ldots \ldots \ldots \ldots \ldots \ldots \ldots \ldots \ldots \ldots \ldots \ldots \ldots \ldots \ldots$ vii

PART I-Practical Rules for Graphic Presentation.............. 3

Section

I. Graphic Representation of Statistical-Business Data........... 6

II. Graphic Representation of Time Series or Quantitative Classification by Means of Absolute Simple Vertical-Bar Charts............. ro

III. Graphic Representation of Qualitative Classification at a Particular Point of Time, or for a Given Period of Time, by Means of Absolute Simple Horizontal-Bar Charts...................... I4

IV. Graphic Representation of Time Series or Quantitative Classification by Means of Component Vertical-Bar Charts.............. I9

V. Graphic Representation of Qualitative Classifications by Means of Component Horizontal-Bar Charts.

VI. Graphic Representation of Quantitative or Qualitative Classification by Means of Component Pie-Diagram Charts.............. 30

VII. Graphic Representation of Time Series by Means of Line-Diagram Charts

VIII. Graphic Representation of Qualitative or Quantitative Classification by Means of Three-Dimensional Charts................ 44

IX. Graphic Representation of Statistical Data by Means of Pictorial Charts

X. Graphic Representation of Statistical Data by Means of Maps..... 52

PART II-Examples of Charts to Fit Various Size Publications........ 57

I. Charts for an $81 / 2$ " by $\mathrm{II}^{\prime \prime}$ Page Publication............... $5^{8}$

II. Charts for a 6 " by 9 " Page Publication................. 72

III. Charts for a $6 \frac{1 / 2}{2}$ by $9 \frac{1 / 2}{2}$ " Page Publication.............. 8o

Appendices

A. Table A............................ following 82

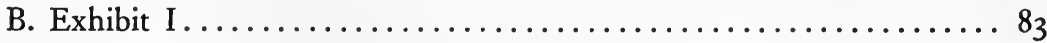

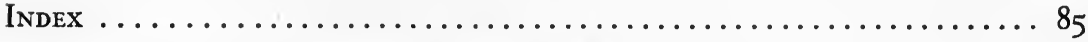

Bureau of Business Research Publications................. 87 


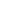




\section{LIST OF CHARTS}

Chart

I Industrial Consumption and Retail Deliveries of Bituminous Coal, United States, 1933-1941....................... I I

IA Number of Workers, By Wage Rate, Ohio, $1936 \ldots . . . \ldots \ldots$...... I3

2 Value of Products Manufactured in the Ten Leading States, United

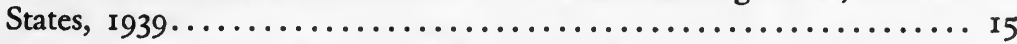

3 Per Capita Value of Products Manufactured, by State, United States, 1939

4 Farm Parity Prices: Per cent August, 1942, Farm Prices Are Above or Below August Parity Prices, Selected Commodities, August, 1942... I 8

5 Gross National Product, By Use of Product, United States, I939-1943 . 2 2 I

6 Percentage Distribution of Gross National Product, By Use of

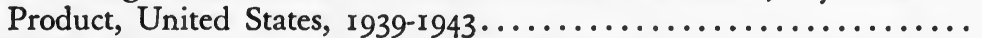

7 Value of Prime War Contracts, By Purpose, Ten Leading States,

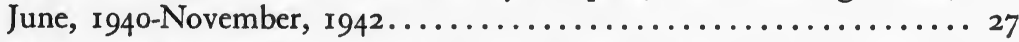

8 Percentage Distribution of the Value of Prime Major War Contracts, By Purpose, Ten Leading States, June, r940-November, 1942...... 29

9 Percentage Distribution of Gross National Product, By Use of

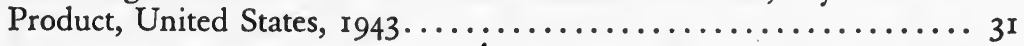

Io Percentage Distribution of Gross National Product, By Use of

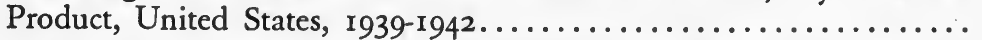

II Value of Products Manufactured in the Two Leading Industries in

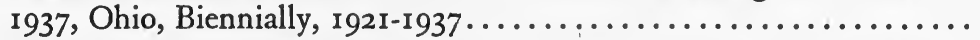

12 Value of Products Manufactured in the Two Leading Industries in

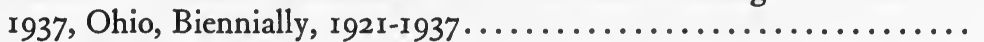

13 Cost of Living of Wage Earners, U. S. and Ohio By Months, 1939-

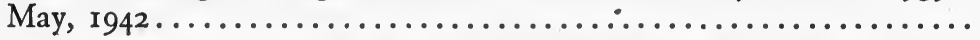

I4 Business Indicators: Indexes of Number Employed, Construction Contracts Awarded, and Bank Debits, Ohio, Annually r933-r94I,

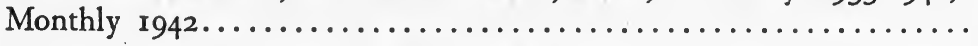

I5 Index of Total Retail Sales, Ohio, I94I-1943 $\ldots \ldots \ldots \ldots \ldots \ldots \ldots$

I6 Per Cent Change in Business Activity, United States, August, 1939 to August, I943.

I7 Value of Products Manufactured and Number of Wage Earners Employed in Manufacturing, Ohio, Biennially, r919-1937....... 43

I8 Claimant Receiving Original Payments, Less Than Maximum Benefits, and Maximum Benefits, Ohio, I939-1943.

19 Distribution of the Unemployment Compensation Contributions,

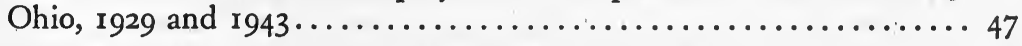

20 Average Weekly Number of Benefit Recipients, Ohio, I940 and 1943 . 49 
Chart

20A Retail Sales, By Major Business Group, Ohio, r $944 \ldots \ldots \ldots \ldots \ldots . \ldots 49$

2I Percentage Distribution of the Value of Major War Supply Contracts, Ohio, Michigan, and Illinois, June, I940 Through July, I944..... 50

2I A Per Cent Change in Retail Sales, By Type of Business, Ohio, 1944

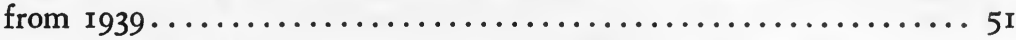

22 Index of the Number Employed in the Food Product Industry, Ohio,

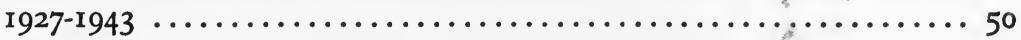

23 Change in Civilian Population of Ohio Counties, April, r940 to

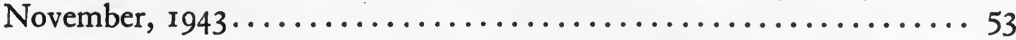

24 Per Cent Change in Selected Business Indicators, United States, June,

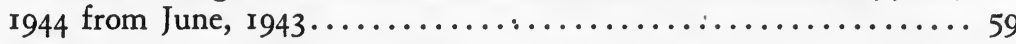

25 Number Employed in the Major Manufacturing Industry Groups,

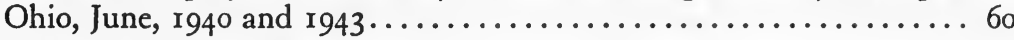

26 Selected Business Indicators, Ohio, First Half r940-r $945 \ldots . . \ldots \ldots$. . 6 r

27 Gross National Product, By Use of Product, United States, I939-I943 . 62

28 Percentage Distribution of Gross National Product, By Use of Product, United States, I939-I943.

29 Per Cent Change in Selected Business Indicators During the First Three Years of the War, United States, August, 1939 to August, 1942. 65

30 Per Cent Change in Average Hourly Earnings in Principal Industries, Ohio, January, I94I to September, I 942 and $1943 \ldots \ldots \ldots \ldots \ldots . . .6$

3I Amount and Percentage Distribution of War Contracts, By Purpose, Selected Areas, Ohio, June, r940-January, I944..............67

32 Wholesale Commodity Price, United States, World War I (I9r4r9r8) and World War II (I939-1943)

33 Sales and Redemption of War Bonds, United States, May, r94I-

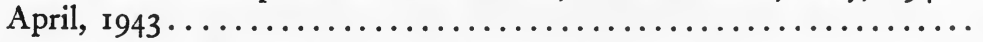

34 Corporate Profit and Net Addition or Reduction in Surplus, United

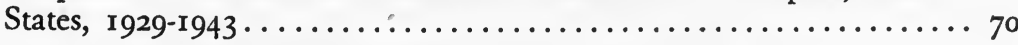

35 Population, United States, Selected Years, rgr5-1945.......... $7^{1}$

36 Wage Loss Replaced by Benefits under the Original (1938) Ohio, Wisconsin, and New York Laws, I3 Companies, Ohio, I928-1932.... 73

37 Wage Loss Replaced by Benefits under the Original Ohio and under 194I Amended Ohio Laws, I3 Companies, Ohio, 1928-r932 ....... 75

38 Percentage Distribution of Men and Women Beneficiaries, By Occupation Groups, Columbus, Ohio, r939-1940................ 77

39 Indexes of Seasonal Employment of Wage Earners in the Dairy Products and Ice Cream Industry and in Industries with Complementary Seasonal Pattern, Cuyahoga County, Ohio, 1926-1936...... 79

40 Indexes of Physical Volume of Production of Manufactures and Minerals Adjusted for Seasonal Variation, United States, I935-I943 . . 81 


\section{PART I \\ PRACTICAL RULES FOR GRAPHIC PRESENTATION}





\section{PART I}

\section{PRACTICAL RULES FOR GRAPHIC PRESENTATION}

The functions of charts are manifold. However, important functions are: (I) to intrigue the imagination of the reader to the point where a desire will be created, first, to read the publication, and second, to go to the tabular data for more complete information; and (2) to emphasize significant relationships because of their importance, since oftentimes these important relations are lost in the multitude of figures in the table. The first function as stated above assumes that, in general, the reader, when in doubt, looks at the charts before deciding whether or not to read the publication, and as such, charts are used by the reader, rightly or wrongly, in order to obtain a quick summary of the article. The second function assumes that "a picture is worth a thousand words" (as the old Chinese saying goes). These functions should be kept in mind when deciding what data should be charted.

Although it is always desirable, and theoretically possible to accompany a table by a chart on which the most significant items in the table are plotted, this course is not always practicable. Time for making or space for publishing numerous charts, or funds for a large undertaking, may one or all be lacking.

If a choice must be made between presenting a table or a chart, as is sometimes the case when writing a short article, the general rule should be:

I. If the analysis deals with precise quantities, omit the chart and use the table.

2. If the analysis is in terms of general trends and relationships, present the chart and omit the table. It should be remembered, however, that a chart is never a substitute for a table, and hence, should not be expected to display the accuracy of tabular data.

Part I includes the rules and regulations necessary for the effective graphic presentation of business data along with examples of the major types of charts (Charts $\mathrm{I}-23$ ).

Part II includes additional examples of charts of various sizes to fit various size publications (Charts 24-40).

Table A (Appendix A) indicates the size of chart before and 
after reduction, and the size of letters before reduction for Charts I-23 included in Part I of this publication, as well as for Charts $24-40$ included in Part II. In order to draw detailed information on a chart, it is often necessary to draw the graph about 2, 3, or even 4 times the desired size for publication. As a result, many of those responsible for the execution of charts are confronted with the problem of deciding what size lettering to use in the title, in the prefatory note, for the scale numerals, etc., so that the original drawing when reduced will have the proper size letering. The data in Table A, along with Charts $1-40$, can be used as guides for solving such problems.

Exhibit I (Appendix B) contains examples of suggested types of hatching as well as suggested combinations of hatching which can be used for component bar charts, band charts, and pie diagrams.

A chart, like a table, has a body or field as well as information above and below the main body, i.e., three general parts. First, in order of appearance, are the parts above the field which include the display title, the title, and the prefatory note. Second are the parts of the field, the chart proper, which include the scale description (designation), scale numerals, grid, scale or guide lines, as well as the qualitative classification, bar description (designation), and the bars in the case of bar charts; and curve lines and curve labels in the case of line diagrams. Third, are the parts below the field which include the footnotes, key, source, and explanatory note.

The rules and principles necessary to the effective graphic presentation of business data are given below in concise outline form. The terminology of the instructions is, for the reader's convenience, embodied in Chart A, which applies to bar charts, and Chart B, which applies to line diagrams. Each of these two graphs has its several parts labeled with the technical designations used in the text. The use of these two charts with the various parts labeled eliminates the necessity of defining in sentence form the parts of a chart.

The rules which apply to the parts above and below the field on all charts are covered in I of the outline below. Also in I of the outline the rules are given for the size and style of the lettering of the various parts which appear in the field, and guides to the dimensions for the grid and to the scaling of the grid. In II through X of the outline the rules are given for specific types of charts. Cross references have been used to avoid repetition. 


\section{CHART A}

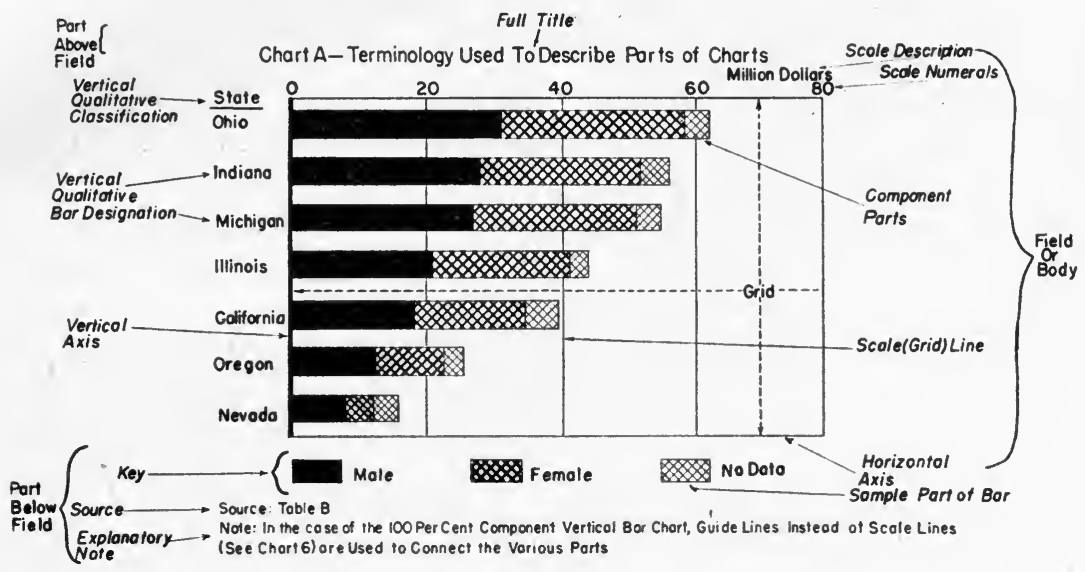

\section{CHART B}

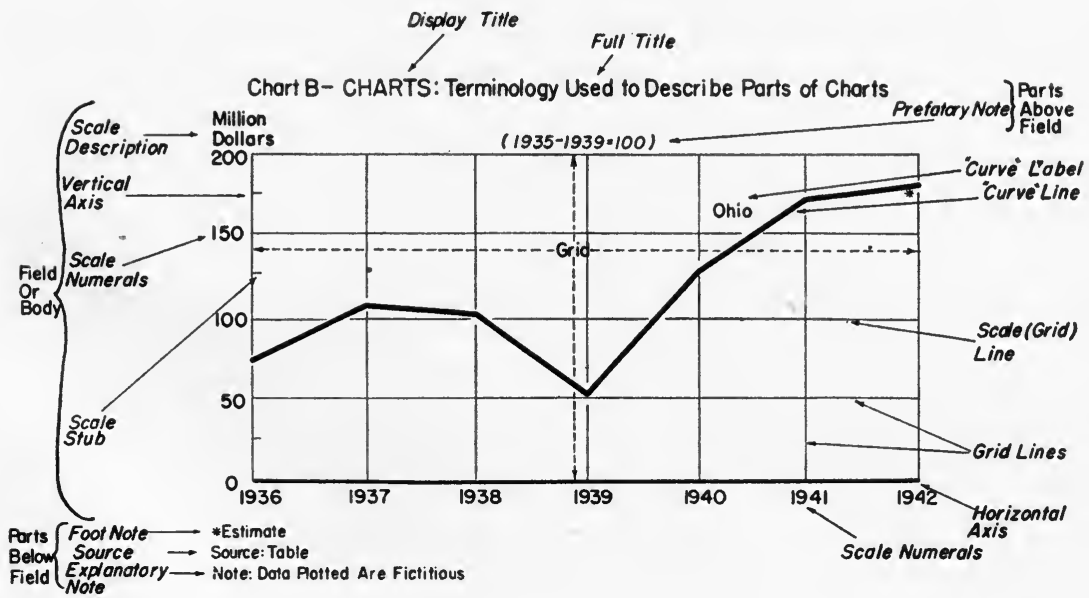




\section{I.GRAPHIC REPRESENTATION OF STATISTICAL- BUSINESS DATA}

\section{Three General Parts of a Chart}

A. Specific rules for any type of chart ${ }^{1}$

I. Parts above the field

a. Display title (see Chart 4)

(I) Should precede full title and should be above the field.

(2) Should be short, not more than one line long.

(3) All words should be in capital leters of uniform size.

(4) Should be used on all charts in the publication if used at all.

b. Full title

(I) Should be above the field or chart proper.

(2) Should include first, what the data are; second, the classification of the data; third, the place or area to which the data apply; and fourth, the period covered by the data.

(3) Should be lettered in inverted pyramid form if two or more lines are needed, or box form.

(4) Uses of capitals and lower case letters in the title

(a) All the words of the title may be in full capitals of uniform size (see Chart $\mathrm{I}$ ).

(b) All words may be in full capitals of two sizes, large capitals initialing the first word and all

${ }^{1}$ A few summarizing remarks may be helpful. In general, the lettering style for all parts of a chart, as far as capital and lower case letters are concerned, should agree unless the full title is done in all capitals of uniform size. In the latter case, the scale description, vertical qualitative classification, curve label, and bar description (designation) should agree with the full title while the prefatory note, footnotes, key, source, and explanatory note are either capital with smaller capitals or capitals with lower case letters.

In general, the relative lettering sizes used on a chart are as folows: The display title should be done with the largest size letter (largest on the chart). The full title should be done with a smaller size letter than that used in the display title. The scale description, scale numerals, vertical qualitative classification, curve label, and bar designation should be done with the same size letter and one which is smaller than that used in the full title. The prefatory note, footnotes, key, source, and explanatory note should be done with the same size letter and one which is smaller than that used in the scale description.

All writing on a chart should be horizontal so that the reader will not have to turn the publication or his head to read the writing.

The use of abbreviations on a chart should be avoided whenever practical as a courtesy to the reader, but if necessary, abbreviate only common words with standard abbreviations. 
other words except articles, conjunctions, and prepositions (see Chart 2).

(c) All words may be in lower case with capitals initialing the first word and all others except articles, conjunctions, and prepositions (see Chart 3).

(d) If a display title precedes the full title, then either method (b) or method (c) should be used in the full title.

c. Prefatory note

(I) Should be centered slightly above the top line of the chart proper (see Chart 13).

(2) Should be enclosed in parentheses.

(3) Should be in lettering smaller than that used in the title or in the scale description.

(4) Should be preferably in italics.

(5) Use of capital and lower case letters

(a) If the full title is in uniform large capitalsI b (4) (a)-any one of the other two styles may be used-I b (4) (b) or I b (4) (c).

(b) If the title is in either of the other stylesI b (4) (b) or $\mathrm{Ib}$ (4) (c)-the style of the prefatory note should correspond.

2. The field

a. Scale description or designation, scale numerals, vertical qualitative classification (description), bar designation (description), and curve label (see Charts I, 2, 3, 4, I3, etc.)

(I) Should follow the style of lettering used in the title.

(2) Size of lettering should be smaller than that used in the title but larger than that used in the prefatory note.

b. The grid

(I) As a workable guide use dimensions such that the grid will be wider than it is long in somewhat the same proportion as 5 is to 3. This guide can be followed most successfully when charting time series (line diagrams). This guide is of course not rigid. 
(2) The scale equivalents should be the same, if at all possible, on all charts in a given publication dealing with a given subject in order that the visual impressions which the reader carries from one chart to another will be valid insofar as the impressions are based on the magnitudes of the fluctuations or the rates or change as shown by the chart.

(3) The line of reference on a chart should be emphasized by a bold ruling. The line of reference represents the scale line from which the distance to the statistical series charted should be read. All bar charts and line diagrams except the semi-logarithmic chart should have a line of reference which is zero in the case of charts showing absolute values, 100 in the case of line diagrams showing index numbers, and zero in the case of charts showing per cent change.

3. Parts below the field

a. Footnotes (see Chart I3)

(I) Should be avoided if possible.

(2) When used, should be put below the field but should precede the key, source, and explanatory note.

(3) Use of capitals and lower case should follow rules of style which apply to the prefatory note, see I c (5).

(4) Should be the same size lettering as in the prefatory note, see I c (3).

b. Key

(I) Should come below the field if no footnotes are used (see Charts 5, 6, 7, etc.).

(2) Should follow footnotes when footnotes are used (see Chart 27).

(3) Use of capitals and lower case should follow rules of style which apply to the prefatory note, see I c (5).

(4) Should be the same size lettering as in the prefatory note, see I c (3). 


\section{c. Source}

(I) Should be put below the field if there is no footnote and if there is no key (see Charts $\mathrm{r}, 2$, etc.).

(2) Should follow footnote when footnote appears and where there is no key (see Chart 13). Should follow the key if a key is used (see Chart 27).

(3) Should, as a general rule, be a table which should be included in the publication. ${ }^{2}$ In this monograph, the table numbers are shown to indicate the position of the source, although the tables are not included in the publication.

(4) Uses of capitals and lower case should follow rules of style which apply to the prefatory note, see I c (5).

(5) Should be the same size lettering as in the prefatory note, see I c (3).

d. Explanatory note (see Chart $\mathrm{r}_{3}$ )

(I) Should follow source.

(2) Should be avoided if possible.

(3) Should be preceded by the word "Note:".

(4) Uses of capitals and lower case should follow rules of style which apply to the prefatory note, see I c (5).

(5) Should be the same size lettering as in the prefatory note, see I c (3).

${ }^{2}$ If the source for the chart is not a table included in the publication, then the citation of the source should give full details as to location of original data (author, title, [place of publication, publisher, date of publication], volume, and page number). 
II. GRAPHIC REPRESENTATION OF TIME SERIES OR QUANTITATIVE CLASSIFICATIONS BY MEANS OF ABSOLUTE SIMPLE VERTICAL-BAR CHARTS ${ }^{3}$

A. Specific rules for any type (see Chart I)

I. See rules under I.

2. Vertical-scale description should be placed above the vertical-scale numerals.

3. Horizontal-scale description is not needed if the numerals are years or any time period such as months or weeks. If, however, the numerals represent quantity rather than time (annual wages or weekly wages, for example), then the scale description should be centered below the scale numerals.

4. Vertical-scale numerals should always be at the left of the grid along the vertical axis but may be at both the left and the right.

5. Horizontal-scale numerals should always be at the bottom of the grid along the horizontal axis.

6. The distance between bars depends upon the number of bars used. The space should be equal to the width or one-half the width of the bar, or multiples of onequarter the width of the bar. In general, make the distance between bars equal to one-half the width of the bar. ${ }^{4}$

7. Space between the border lines of the chart and the first and last bar should be one-eighth of the width of the bar.

8. Relatively light scale (grid) lines should be used.

9. Emphasize the line of reference by a bold ruling. This, in the case of the absolute simple bar chart, is the zero scale line.

Io. In order to avoid optical illusions and to convey correct impressions, the zero scale lines must be shown as the lower limit of the grid, while the top scale should repre-

\footnotetext{
${ }^{3}$ In general, vertical bars, as opposed to horizontal bars, are used if the analysis is of a given factor at various intervals of time or of a given factor progressing from low to high numerical values.

'Bars are contiguous in the case of the histogram which is a graphic representation of a frequency distribution. (A case in point would be a chart showing the number of employees receiving wages, set up by wage classes, that is, by specific wage intervals-see Chart I A.)
} 


\section{CHART I}

\section{CHART I}

INDUSTRIAL CONSUMPTION AND RETAIL DELIVERIES OF BITUMINOUS COAL

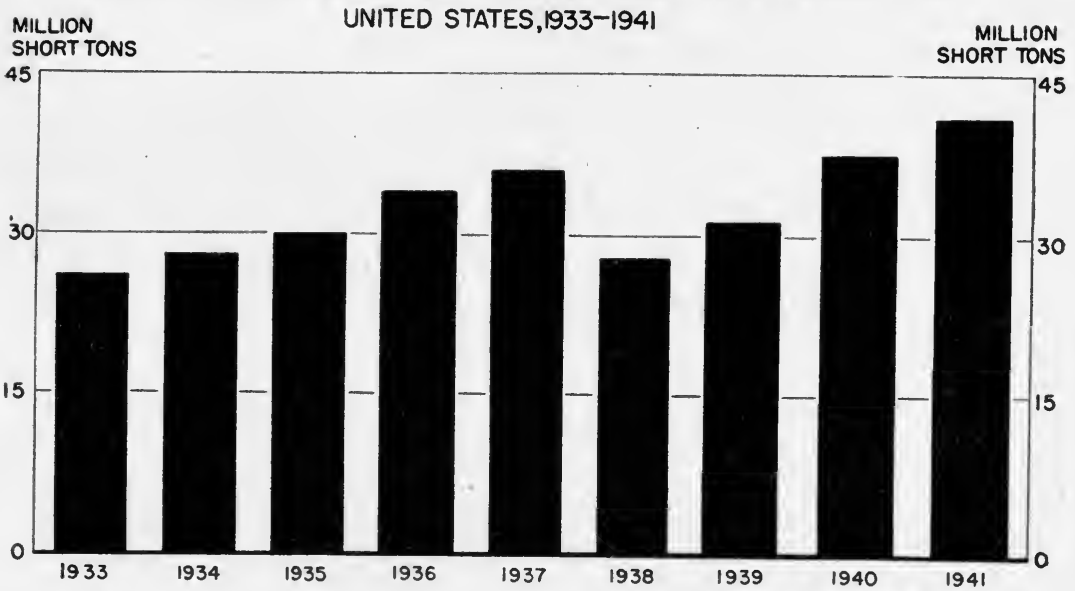

Source:Table I 
sent a value equal to or slightly greater than the highest number to be plotted.

II. Writing between bars or in bars, and putting any numerical data in the chart should be avoided. As a matter of expediency, however, the limited use of some numerical data as well as some writing in the chart may be advisable.

12. Bars are arranged in order of time-that is, the data for the earliest period should appear as the first bar to the left-or, if the data are units for quantitative classifications, such as the number of people receiving specified weekly wages, then the bars should be arranged in order of classification from smallest to highest wage. Thus, the first bar to the left would represent the number of people receiving the smallest weekly wage and the other bars would follow in order of magnitude of the weekly wage. If the latter is a frequency distribution, the bars should be contiguous (see Chart IA). 


\section{CHART IA}

Chart IA - Number Of Workers, By Wage Rate, Ohio, 1936

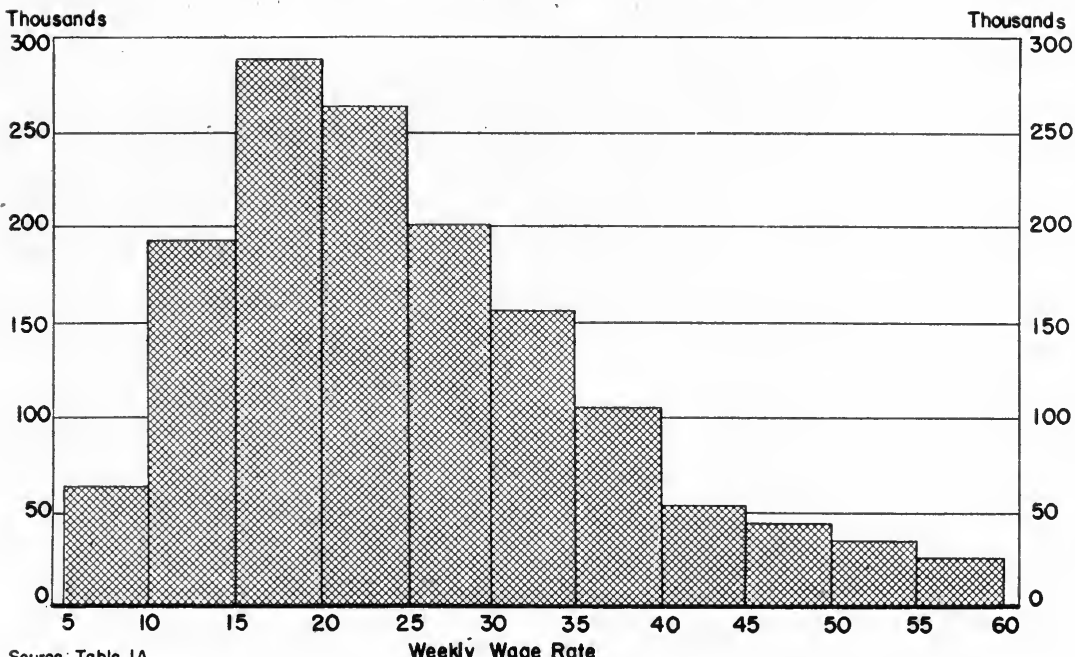

Source: Table IA 
III. GRAPHIC REPRESENTATION OF QUALITATIVE CLASSIFICATIONS AT A PARTICULAR POINT OF TIME, OR FOR A GIVEN PERIOD OF TIME, BY MEANS OF ABSOLUTE SIMPLE HORIZONTAL-BAR CHARTS $^{5}$

A. Specific rules for any type (see Chart 2 for simplest type)

I. See rules under I.

2. Horizontal-scale description should be placed above the horizontal-scale numerals.

3. The designation of the classification (description) should be centered above the classes descriptive of the bars (bar designation) and should be underscored. The designation of the classification should be on a level with the horizontal-scale description.

4. Horizontal-scale numerals should always be at the top of the grid, but, if the chart is very long, may be at both the top and the bottom along the horizontal axis.

5. The distance between bars depends upon the number of bars used. The space should be equal to the width or one-half the width of the bar, or multiples of one-quarter the width of the bar. In general, the distance between bars should be equal to one-half the width of the bar.

6. Space between the border lines of the chart and the first and last bar should be one-eighth the width of the bar.

7. Relatively light scale (grid) lines should be used.

8. Emphasize the line of reference by a bold ruling. This, in the case of the absolute simple bar chart, is the zero scale line.

9. In order to prevent optical illusions and to convey proper impressions, the zero grid line must be shown as the lower limit of the scale (unless negative values are plotted), while the upper limit of the scale should represent a value equal to or slightly greater than the highest number to be plotted.

I0. Writing between bars or in bars and putting any numerical data in the chart should be avoided. As a matter of expediency, however, the limited use of some nu-

${ }^{5}$ In general, horizontal bars, as opposed to vertical bars, are used if the analysis is of various factors (qualitative) at a particular point of time or for a given period of time. 


\section{CHART 2}

Chart 2 - Value of Products manufactured in the ten leading States, UNITED STATES, 1939

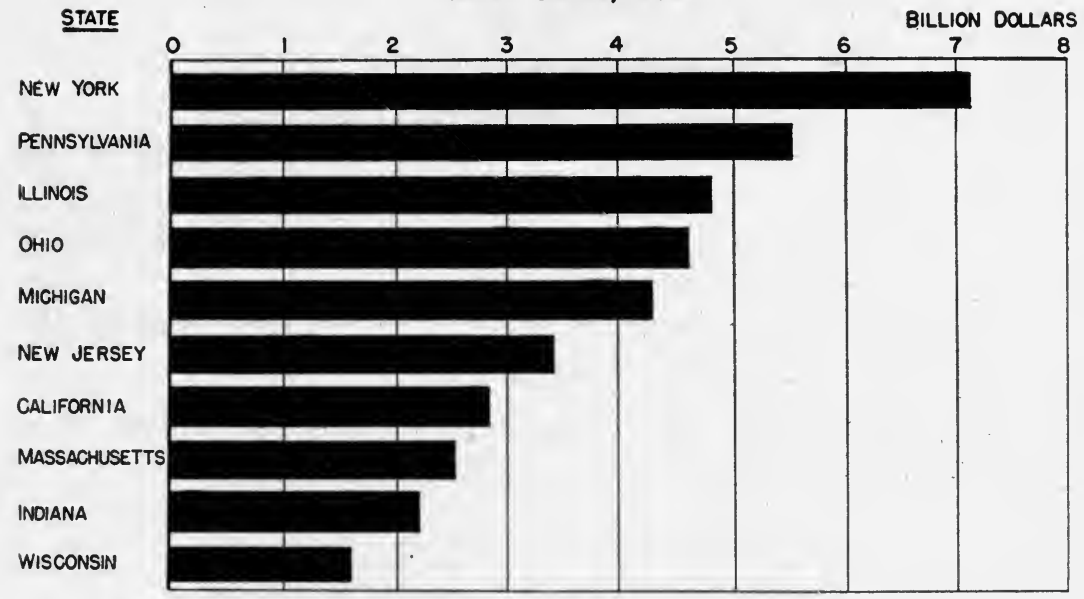

SOURCE : TABLE 2 
merical data as well as some writing in the chart may be advisable.

II. Bars should be arranged in some systematic order to facilitate analysis. The order may be that of magnitude, geographic, customary, etc. The usual order is that of magnitude.

B. Specific rules for many-item horizontal-bar charts (see Chart 3)

I. See rules under III, A.

2. Width of the bar should be relatively narrow.

3. Scale lines should be dropped off toward the lower right as the bars become shorter.

4. Two such charts can sometimes be dovetailed on one page.

5. The title may be put either at the top or in the vacant space in the field of the chart.

6. As a general rule, bars should be arranged from the top down in order of magnitude.

C. Specific rules for bilateral horizontal-bar charts (see page 18) 


\section{CHART 3}

Chart 3- Per Capita Value of Products Manufactured, by State, United States, 1939 State

Michigan .

New Jersey

Rhode island

Connecticut

Ohio

Indiana

Illinois

Massachusetts

Morylond

Pennsylvania

New York

Wisconsin

New Hampshire

Delaware

Moine

Colifornio

North Corolino

Virginio

Missouri

Woshington

Oregon

Utah

Minnes ota

Vermont

lowa

Montona

Konsos

Tennessee

Louisiona

Texos

West Virginio

Georgio

South Corolino

Nebrosko

Alobomo

Colorado

Arizono

Nevada

Wyoming

Idaho

Kentucky

Oklahomo

Florido

South Dakoto

Arkansas

Mississippi

North Dakota

New Mexico

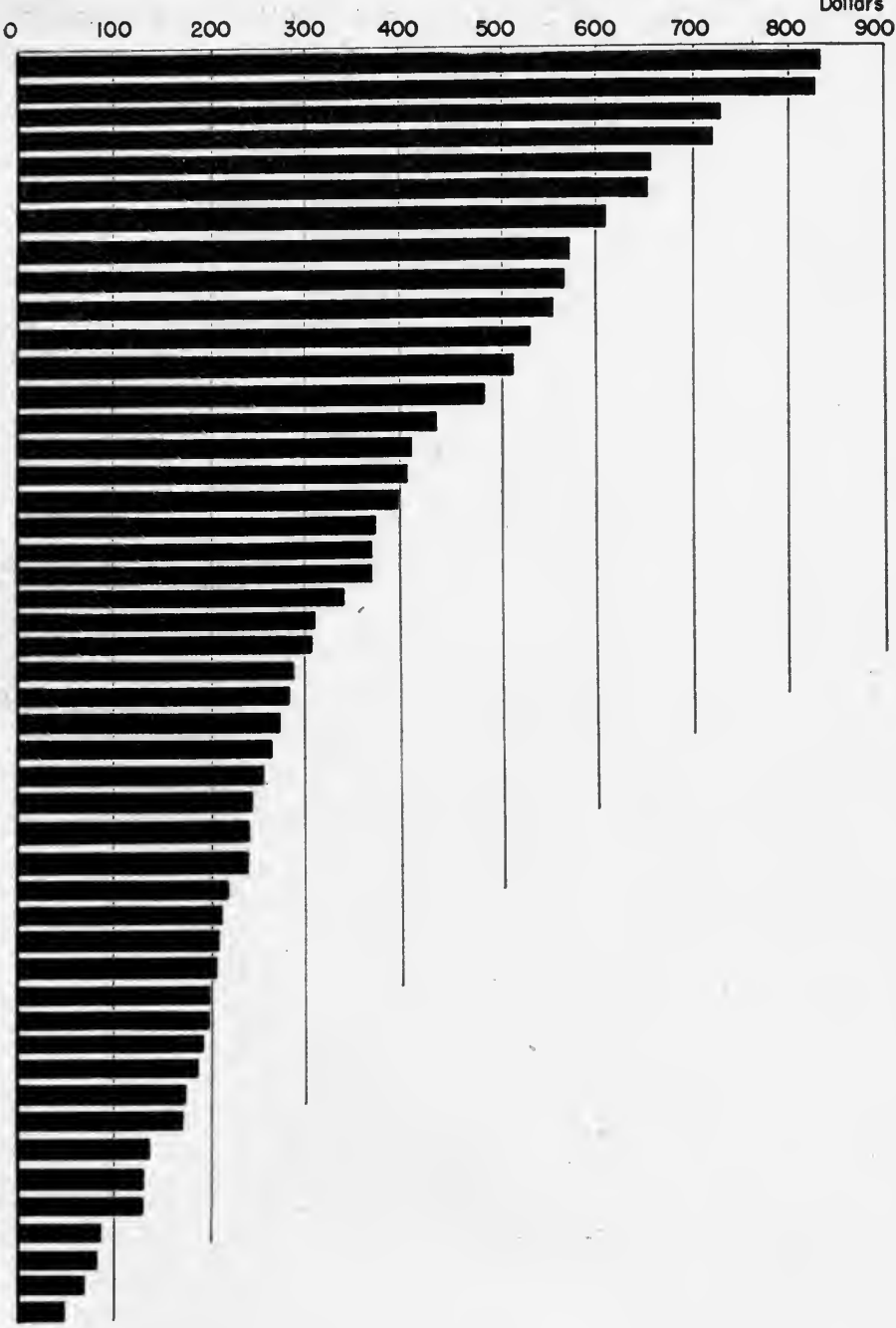

Source: Toble 3 
C. Specific rules for bilateral horizontal-bar charts (see Chart 4)

I. See rules under III, A.

2. Scale lines should be dropped off as the bars become shorter.

3. As a general rule, bars should be arranged from the top down in order of magnitude.

\section{CHART 4}

\section{Chart 4}

FARM PARITY PRICES: Per Cent August, 1942, Farm Prices Are Above or Below August Parity Prices, Selected Commodities, August, 1942

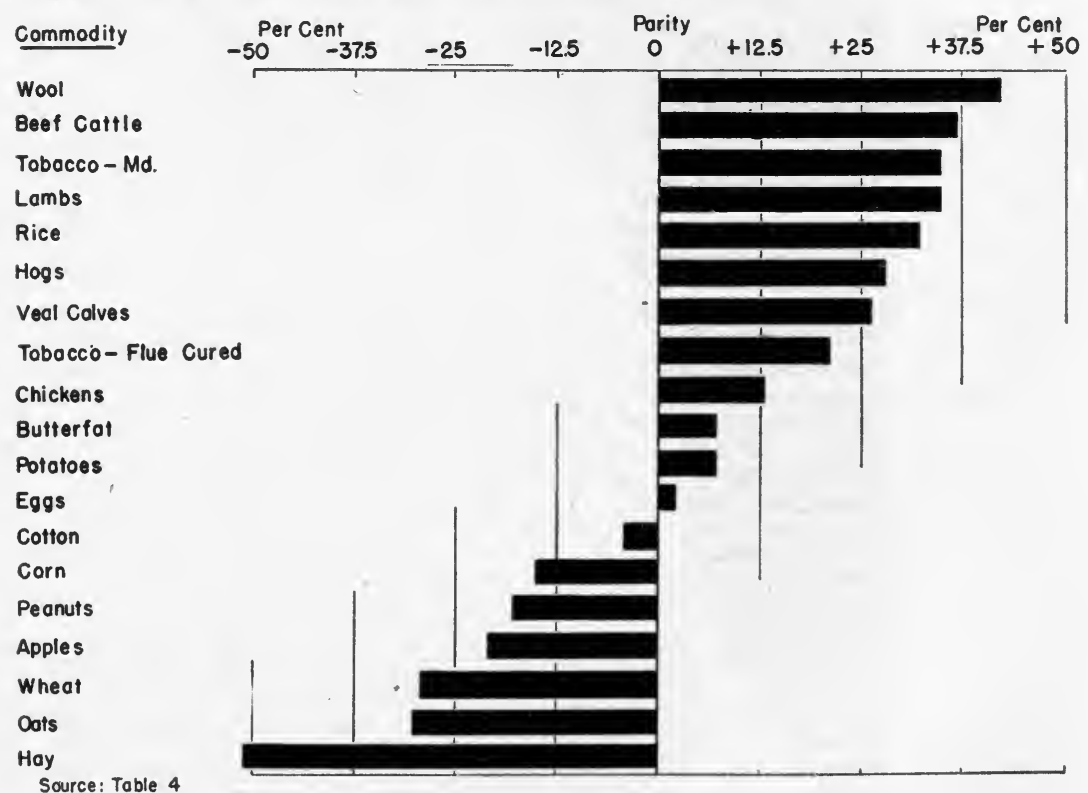

Source: Table 4 
IV. GRAPHIC REPRESENTATION OF TIME SERIES OR QUANTITATIVE CLASSIFICATION BY MEANS OF COMPONENT VERTICAL-BAR CHARTS

A. Specific rules for any type

I. See rules under I.

2. Vertical-scale description should be placed above the vertical-scale numerals.

3. Horizontal-scale description is not needed if the numerals are years or any time period such as months or weeks. If, however, the numerals represent quantity rather than time (annual wages or weekly wages, for example), then the scale description must be centered below the scale numerals.

4. Vertical-scale numerals should always be at the left of the grid along the vertical axis, but may be at both the left and the right of the grid.

5. Horizontal-scale numerals should always be at the bottom of the grid along the horizontal axis.

6. The distance between bars depends upon the number of bars used. The space should be equal to the width or one-half the width of the bar, or multiples of onequarter the width of the bar. In general, make the distance between bars equal to one-half the width of the bar. $^{6}$

7. Space between the border lines of the chart and the first and last bar should be one-eighth the width of the bar.

8. Emphasize the line of reference which is the zero scale line by a bold ruling.

9. In order to prevent optical illusions and to convey correct impressions, the zero scale line must be shown as the lower limit of the grid, unless negative values are plotted, while the upper limit of the grid should represent a value equal to or slightly greater than the highest number to be plotted.

I0. In general, writing between bars or in bars and putting any numerical data in the chart should be avoided.

${ }^{6}$ Data which lend themselves to bar charts such as these can also be shown as "band charts." The only difference in the rules being that instead of bars, points are plotted for each component part for each month or year, depending on the data, and these points are connected with straight lines. The areas between the lines are hatched (see Chart 34). 
II. Bars are arranged in order of time-that is, the data for the earliest period should appear at the first bar to the left. If the data are units for quantitative classifications, such as weekly wages, then the bars should be arranged in order of classification from smallest to highest wage.

12. The order of the component parts should follow some analytical pattern that will facilitate comparisons. Ordinarily, the largest component is placed at the bottom of the bar and is followed by the next largest component part and so on, depending upon the number of component parts which make up the total. Other arrangements such as geographical, customary, etc., may be used if comparisons would be facilitated or made more significant.

13. The first bar to the left is used as the control, that is, the order of the various parts and the hatchings used in the first bar is maintained for the other bars.

14. Hatching (shading) should proceed from dark at the line of reference to lighter and lighter as the eye travels upward (see example of various hatchings, Exhibit I, Appendix B).

15. The key consists of sample blocks of the hatchings used, each followed by a statement of its specific meaning. The sample blocks which make up the key should be in series from the darkest at the bottom to the lightest.

B. Specific rules for absolute component vertical-bar charts (see Chart 5)

I. The use of this type of chart should be discouraged because it does not lend itself to the type of comparisons which are usually sought. Relative comparisons over time periods, as are ordinarily attempted cannot be made easily from such a chart.

2. See rules under IV, A.

3. Relatively light scale (grid) lines should be used.

4. The bars are of varying size depending upon the absolute values.

${ }^{7}$ It is sometimes feasible to make the last bar of the chart serve as the key by writing the explanation of the parts along the side of the various parts of the last bar. 


\section{CHART 5}

CHART 5 - GROSS NATIONAL PRODUCT, BY USE OF PRODUCT, UNITED STATES, 1939-1943
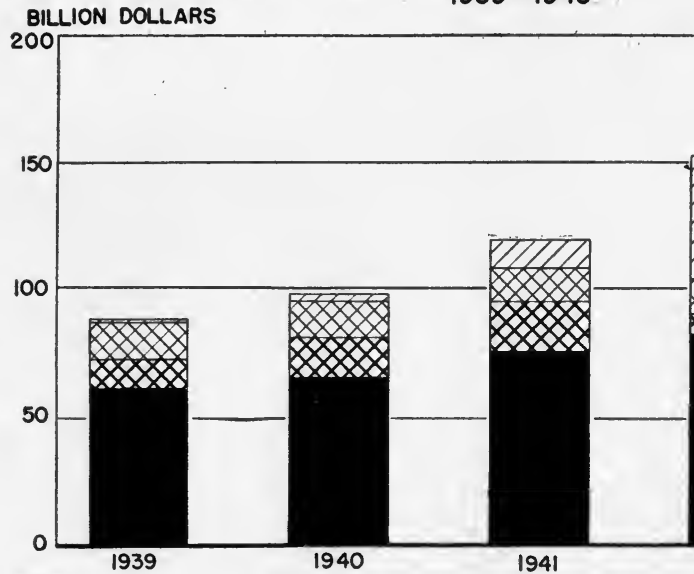

BILUN DOLLARS

194

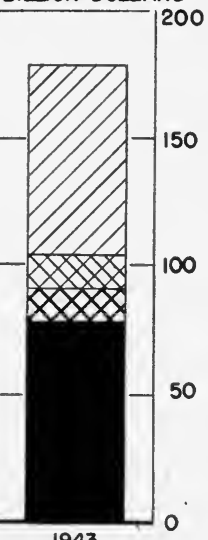

GOVERNMENT NONWAR

DZGovernment war SOURCE : TABLE 5 
C. Specific rules for roo-per-cent component vertical-bar charts (see Chart 6)

I. This desirable type of chart shows the relative change in importance of the various component parts, which is usually the type of comparison desired by the reader.

2. See rules under IV, A.

3. Scale stubs should not extend to the bar.

4. Relatively light guide lines (not scale línes) to connect the various part of the bar should be used. Since the position of the various parts of the bars is fixed, a picture of trend can be obtained by the use of guide lines.

5. All bars are of the same size, namely, each bar is equal to 100 per cent. 


\section{CHART 6}

CHART 6 - PERCENTAGE DISTRIBUTION OF GROSS NATIONAL PRODUCT, BY USE OF PRODUCT, UNITED STATES, 1939-1943

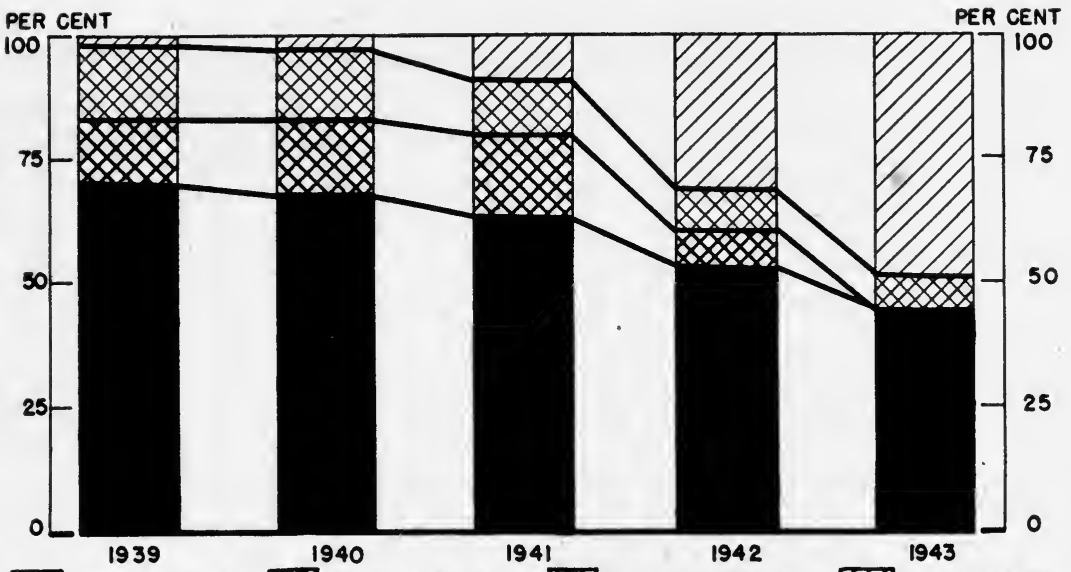

Consumers Goods Groducers Goods Government Nonwor DGovernment Wor Source: Toble 6 


\section{V.GRAPHIC REPRESENTATION OF QUALITATIVE CLASSIFICATIONS BY MEANS OF COMPONENT HORIZONTAL-BAR CHARTS}

\section{A. Specific rules for any type}

I. See rules under I.

2. Horizontal-scale description should be placed above the horizontal-scale numerals.

3. The designation of the classification (description) should be centered above the classes descriptive of the bars (bar designation) and should be underscored. The designation of the classification should be on a level with the horizontal-scale description.

4. Horizontal-scale numerals should always be placed at the top of the grid, but if the chart is very long, may be at both the top and the bottom along the horizontal axis.

5. The distance between bars depends upon the number of bars used. The space should be equal to the width or one-half the width of the bar, or some multiple of onequarter the width of the bar. In general, make the distance between bars equal to one-half the width of the bar.

6. Space between the border lines of the chart and the first and last bar should be one-eighth the width of the bar.

7. Emphasize the line of reference which is the zero scale line by a bold ruling.

8. In order to avoid optical illusions, and in order to convey proper impressions, the zero line must be shown as the lower limit of the scale, unless negative values are shown, while the upper limit of the scale should represent a value equal to or slightly greater than the highest number to be plotted.

9. Writing between bars or in bars, or putting any numerical data in the chart should be avoided. For such numerical details, the reader should consult the table. As a matter of expediency, however, exceptions may sometimes be advisable (see Chart r8).

Io. Bars should be arranged in some systematic order to facilitate analysis. The order may be magnitude, geographic, customary, etc. 
II. The order of the component parts should follow some analytical pattern that will facilitate comparisons. Ordinarily the largest component is placed at the left and is followed by the next largest component part, and so on depending upon the number of component parts which make up the total, but other arrangements may be used.

I2. The first bar at the top is used as the control, that is, the order of the various parts and the hatchings used in the first bar is the control for the other bars.

I3. Hatching (shading) should proceed from dark at the line of reference (zero scale line) to lighter and lighter as the eye moves from left to right (see sample of various hatchings-Exhibit I, Appendix B).

I4. The key consists of sample blocks of the hatchings used, each followed by a statement of its specific meaning. The sample blocks which make up the key should be in series from the darkest at the left to the lightest. ${ }^{8}$

B. Specific rules for absolute component horizontal-bar charts (see page 26)

${ }^{8}$ It is sometimes feasible to make the bottom bar of the chart serve as the key by writing the explanation of the parts below the various parts of the bottom bar (see Chart 2I). 
B. Specific rules for absolute component horizontal-bar charts (see Chart 7)

I. The use of this type of chart should be discouraged because it does not lend itself to the type of comparisons which are usually sought. Relative comparisons as are ordinarily attempted cannot be made easily from such a chart.

2. See rules under $\mathrm{V}, \mathrm{A}$.

3. Relatively light scale (grid) lines should be used.

4. Bars are of varying, size depending upon the absolute values.

C. Specific rules for Ioo-per-cent component horizontal-bar charts (see page 28) 


\section{CHART 7}

CHART 7-VALUE OF PRIME WAR CONTRACTS, BY PURPOSE,

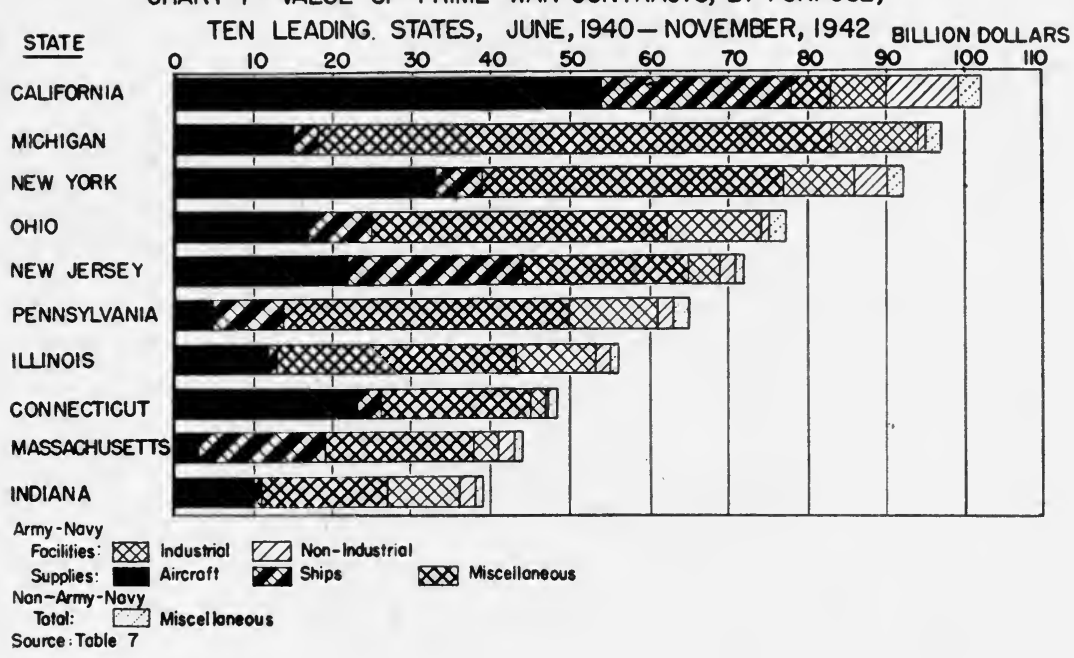


C. Specific rules for 10o-per-cent component horizontal-bar charts (see Chart 8)

I. This desirable type of chart shows the relative importance of the various parts, which is usually the type of comparison desired by the reader.

2. See rules under V, A.

3. Relatively light scale (grid) lines should be used. Guide lines should not be used unless the interpretation is to be made in terms of the relative importance of each part as between the items in the "stub.".

4. All bars are of the same size, namely, each bar is equal to roo per cent. 


\section{CHART 8}

CHART 8- PERCENTAGE DISTRIBUTION OF THE VALUE OF PRIME MAJOR WAR CONTRACTS, BY PURPOSE, TEN LEADING STATES, JUNE, 1940 - NOVEMBER, 1942

$\begin{array}{llllllllllll}\text { STATE } & \text { PER CENT } & & & & & & & & & & \\ 10 & 20 & 30 & 40 & 50 & 60 & 70 & 80 & 90 & \text { PER CENT }\end{array}$

CALIFORNIA

MICHIGAN

NEW YORK

OHIO

NEW JERSEY

PENNSYLVANIA

ILLINOIS

CONNECTICUT

MASSACHUSETTS

INDIANA

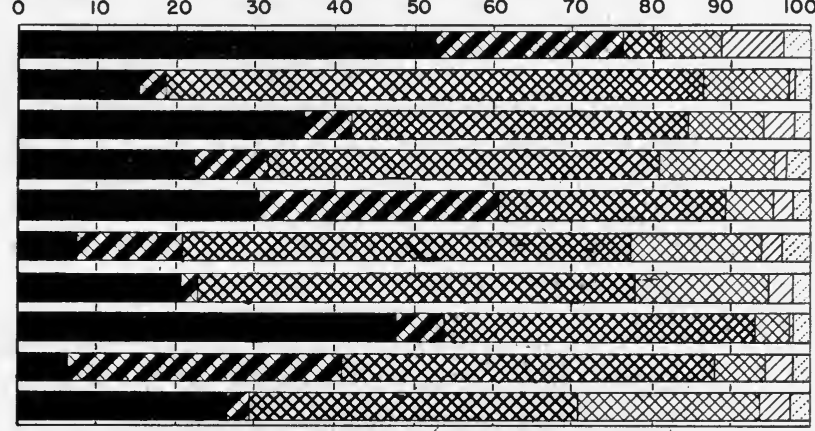

Army-Navy
Facilities:
Supplies: $\cdots$ Industrial
Aircraft

18. Miscellaneous

Non- Army - Novy

Total

Miscellaneous

Source : Table 8 
VI. GRAPHIC REPRESENTATION OF QUANTITATIVE OR QUALITATIVE CLASSIFICATION BY MEANS OF COMPONENT PIE-DIAGRAM CHARTS

A. Specific rules for any type (see Charts 9 and ro)

I. See rules under I.

2. If only one circle is to be shown, it can be either an absolute or roo-per-cent component pie-diagram. If, however, two or more circles are to be shown, each should be on a percentage basis, i.e., roo-per-cent component pie-diagram, for comparisons between the parts of two or more circles with varying areas (the case if absolute values are plotted) are difficult.

3. If the chart consists of two or more pie-diagrams, the space between them should equal the diameter or radius of the circle and each circle designation should be centered below.

4. At least four scale numerals should be shown on each pie-diagram.

5. Writing any numerical data in the pie-diagram should be avoided. For such numerical details, readers should consult the source table. As a matter of expediency, exceptions may sometimes be advisable (see Chart 19).

6. Pie-diagrams should be arranged in some systematic 


\section{CHART 9}

CHART 9 - PERCENTAGE DISTRIBUTION OF GROSS NATIONAL PRODUCT, BY USE OF PRODUCT, UNITED STATES, 1943

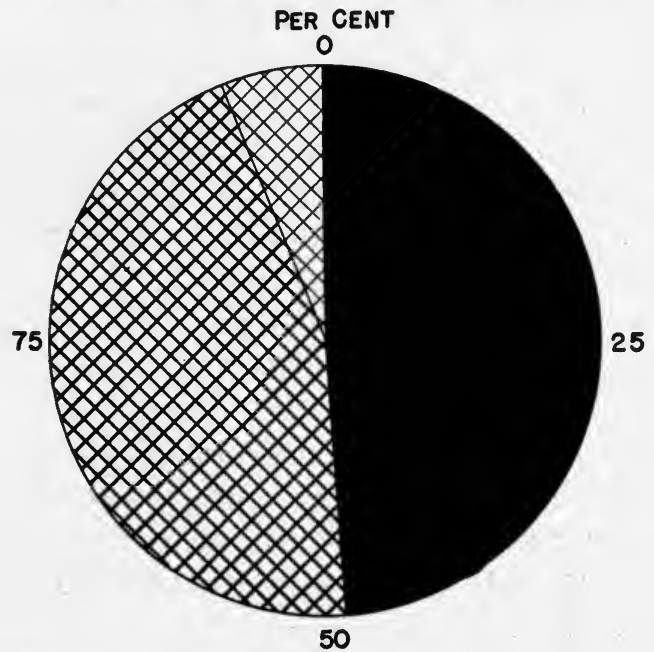

GOVERnMENT WAR 88 CoNSUMERS GOODS GÖVERMENT NONWAR

SOURCE: TABLE 9 
order to facilitate analysis. The order may be that of time, geographic, customary, etc.

7. Order of the component parts should follow some regular pattern and should be the same in all circles. Ordinarily, the largest component should come first and the other components should be introduced clockwise. Some other arrangement may be followed if it is more significant.

8. Hatching (shading) should decrease from dark to light as the eye moves clockwise (see sample of various hatchings, Exhibit I, Appendix B).

9. All roo-per-cent component pie-diagrams are of the same size, but absolute component pie-diagrams vary in size. The latter type of pie-diagram should be avoided.

Io. The key consists of sample blocks of the hatchings used, each followed by a statement of its specific meaning. The sample blocks which make up the key should be in series from the darkest at the left or bottom to the lightest. ${ }^{9}$

II. More than one or two pie-diagrams in one chart should be avoided because comparisons of parts from circle to circle are difficult. (A better type of chart to show similar data is the roo-per-cent component bar chart.)

${ }^{8}$ It is sometimes feasible, particularly if the pie-diagram is divided into only two parts, to put the explanation of the various parts of the pie-diagram along the side of one of the circles (see Chart I9). 


\section{CHART Io}

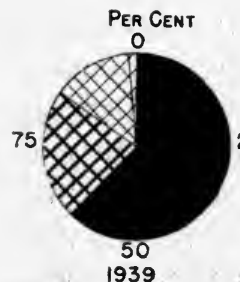

1939

\section{5}

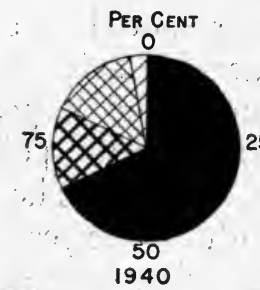

XXOPODURS GOODS
25

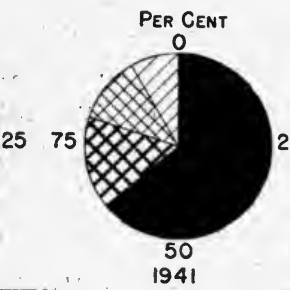

GOVERNMENT NONWAR
2575

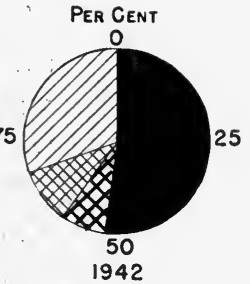

SOURCE: TABLE 10 


\section{GRAPHIC REPRESENTATION OF TIME SERIES BY MEANS OF LINE-DIAGRAM CHARTS}

A. Specific rules for any type

I. See rules under I.

2. Vertical-scale description should be placed above the vertical-scale numerals.

3. Horizontal-scale description is not needed if the numerals are years. If, however, months are plotted, then the scale description might be indicated below the scale numerals.

4. Horizontal-scale numerals should be at the bottom of the grid along the horizontal axis. If the horizontalscale value is to be changed for purposes of emphasis, the chart should be broken at the point of change to caution the reader (see Chart I4). The horizontal timescale may be the 12 months of the year. This time-scale is an effective one for showing seasonal pattern as well as short-term trend. (Not more than 3 or 4 years, which means 3 or 4 lines, should be plotted on this type of chart-see Chart 15$)^{10}{ }^{10}$

5. Relatively light and few scale (grid) lines should be used.

6. The "curve" lines should be heavy straight lines connecting the various observation points. They should not be smoothed unless according to some mathematical formula.

7. If more than one curve appears on the chart, and if the curves cross, one solid-line curve should represent the item which is to be emphasized and the other should be a broken line (see Chart II). If, however, the curves do not cross, both may be solid (see Chart I2).

8. If annual data are plotted, the first year should be located on the first vertical line (see Chart II). If, however, monthly data are being plotted, the first month (January), should be located not on the first vertical

${ }^{10}$ If time is plotted along the horizontal axis, two different sets of time can be shown in the same area. One time series would be based on one time period, while another series would be based on a different neriod of time (see Chart 32). 


\section{CHART II}

CHART II- VALUE OF PRODUCTS MANUFACTURED IN THE TWO LEADING INDUSTRIES

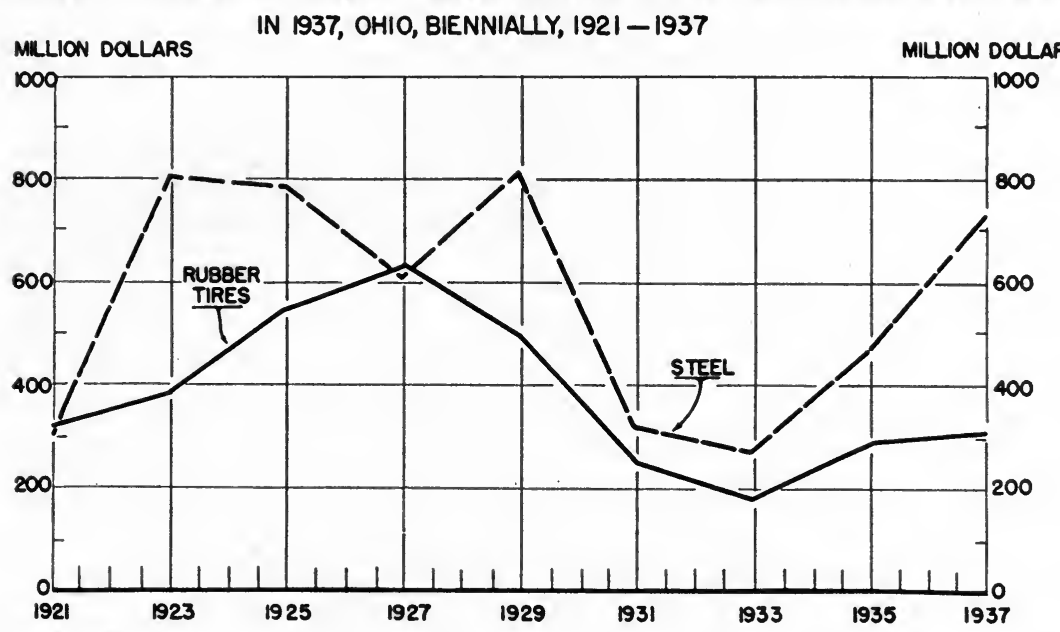

Source : Toble II 
line but one month to the right so that the chart can be laid-off into even quarters of a year (see Chart 13).

9. The scale or grid lines should be broken at the intersections with the "curve" line and also with the "curve" label.

B. Specific rules for absolute (arithmetic) vertical-scale linediagram charts (see Charts II and I2)

I. See rules under VII, A.

2. Vertical-scale numerals along the vertical axis should always be at the left of the grid but may be at both the left and the right. The use of two different sets of vertical-scale values, one on the left and one on the right, unless properly proportioned, on any arithmetic chart should be avoided in order to maintain integrity in the chart. Double scales may be used on a log chart (see under VII, D below).

3. The line of reference, which in the case of the line diagram with arithmetic absolute scale values is the zero scale line, should be a bold ruling for emphasis.

4. The curve label should be placed in the grid whenever practical, preferably above the curve, in order to facilitate reading the distances from the zero line to the curve. Arrows may be used, for the sake of clarity, from the curve label to the curve line (see Chart II).

5. On any arithmetic chart, the distance to be read is from the zero line to the curve. Only amounts of change and not rates of change can be read from this chart.

6. In order to avoid optical illusions, and in order to convey proper impressions, the zero grid line must be shown as the lower limit of the scale (unless negative values are plotted in which event the largest negative value should be shown as the lower limit of the scale) while the upper limit of the scale should represent a value equal to or slightly greater than the highest number to be plotted.

7. Absolute arithmetic scales should not be used to plot two statistical series if one series is so much greater in value than the other that the fluctuations in the smaller series are lost. Log scales can be used (see VII, D be- 


\section{CHART I2}

Chart 12-Value of Products Manufactured in the Meat Packing and Bread

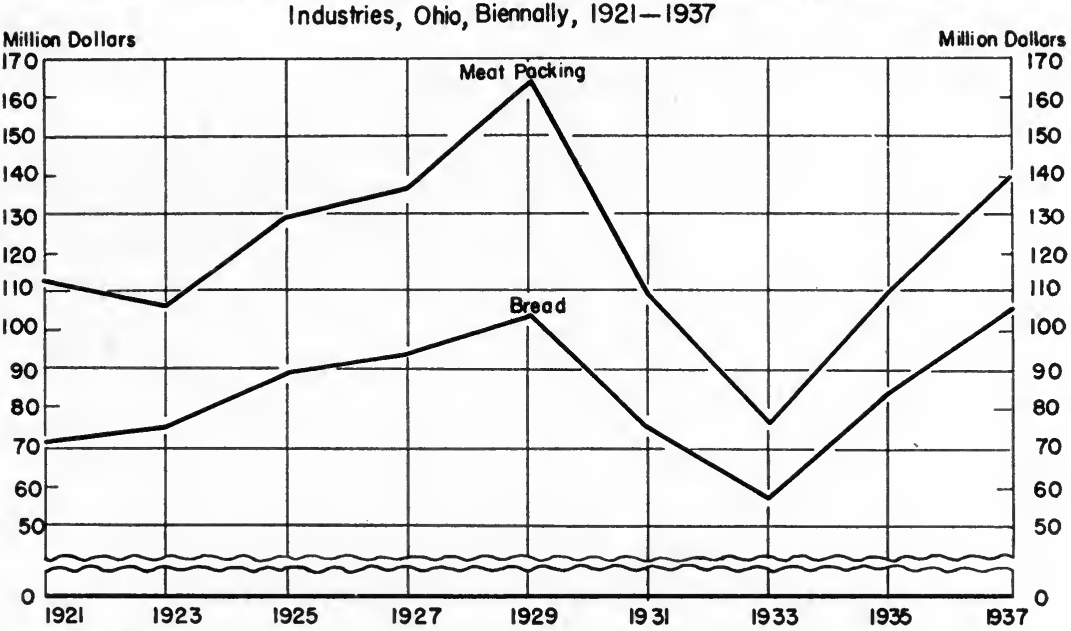

Source: Toble 12 
low), or the two series can be put in the form of index numbers and charted (see VII, C below).

8. If some scale values are to be left off the chart, use two wavy broken lines to warn the reader that some scale values have been omitted (see Chart I2). In general, avoid the omission of scale values/on arithmetic charts, because, on any arithmetic chart, the distance from the zero line to the curve is significant and not the slope of the curve. Hence, if part of the distance (scale values) is omitted, only the very careful reader will get the proper impressions from the chart.

C. Specific rules for percentage (arithmetic) vertical-scale linediagram charts (see Charts 13, I4, 15, and 16)

I. See rules under VII, A.

2. Vertical-scale numerals along the vertical axis should always be at the left of the grid but may be at both the left and the right. The use of two different sets of vertical-scale values, one on the left and one on the right, unless properly proportioned, on any arithmetic chart should be avoided for the sake of integrity. Double scales may be used on log charts (see VII, D below).

3. Emphasize the line of reference which in the line diagram of index numbers is the roo-per-cent scale line (see Chart 13), while in the diagram showing the per cent change, it is the zero scale line (see Chart i6).

4. The curve label should be placed in the grid whenever practical, preferably above the curve in order not to break the distance from the roo-per-cent-scale line for index numbers, and from the zero line in the diagram showing per cent change. Arrows may, for the sake of clarity, be used from the curve làbel to the curve line.

5. On an arithmetic chart showing index numbers, the distance from the roo-per-cent-scale line to the curve and not the slope of the curve is significant. Hence, the chart should start with the scale value of roo or less, depending on the lower limit of the index numbers plotted, while the upper limit of the scale should represent a value equal to or slightly greater than the highest index number charted.

D. Specific rules for logarithmic charts (see page 42) 


\section{CHART I3}

CHART I3-COST OF LIVING OF WAGE EARNERS, U.S. AND OHIO BY MONTHS, 1939 - MAY, 1942

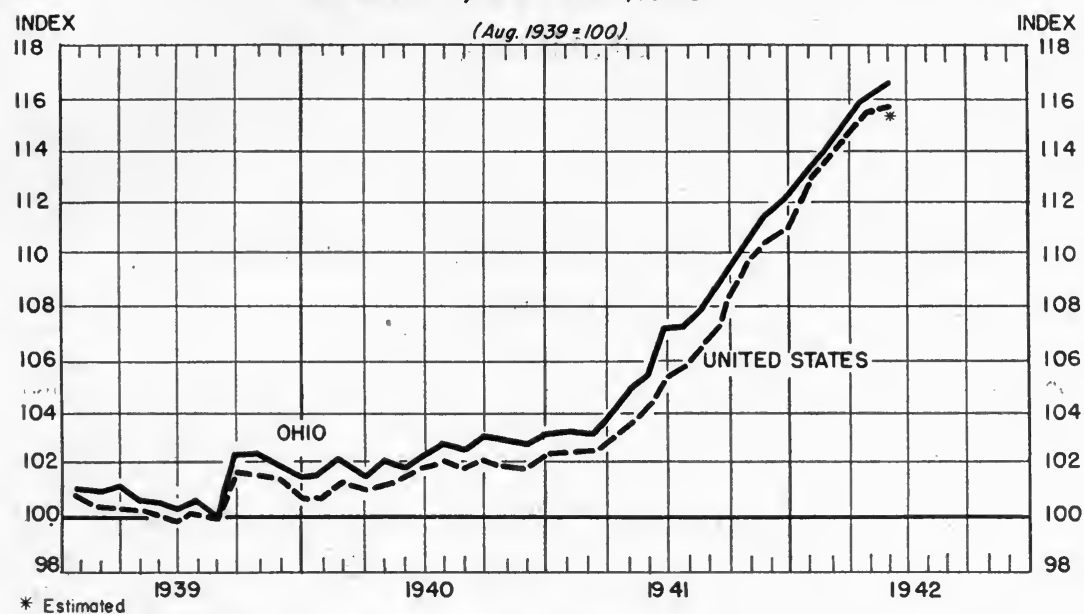

Estimoted

Source: Table 13

Note: Index Converted From January, 1939=100 To August, 1939=100

\section{CHART I4}

Chart 14-BUSINESS INDICATORS: Indexes of Number Employed, Construction Contracts

Awarded, and Bank Debits, Ohio, Annuallv 1933-1941, Monthly 1942

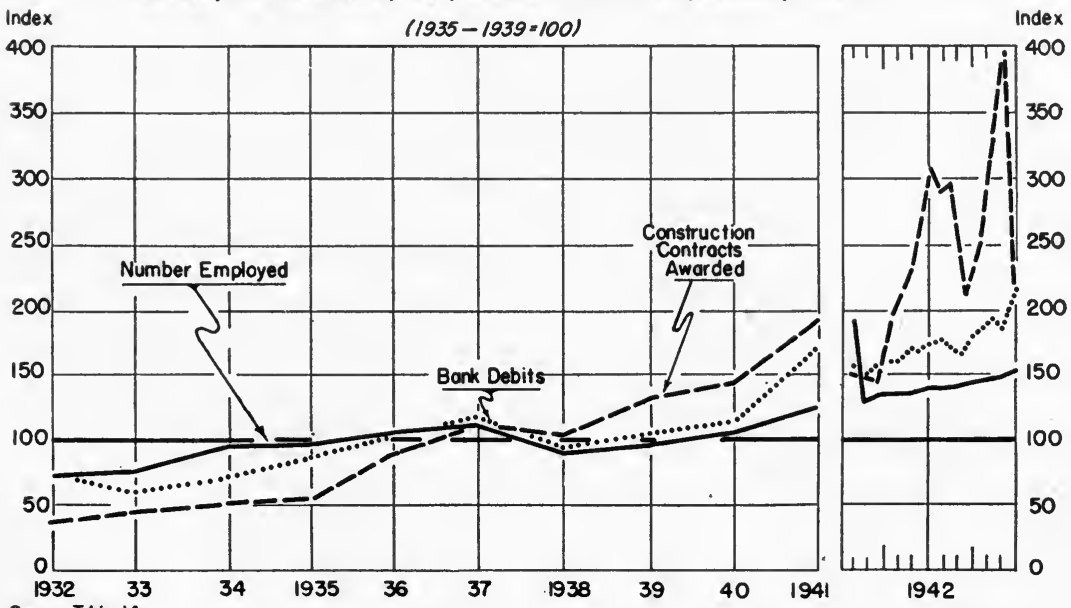




\section{CHART 15}

CHART 15 - INDEX OF TOTAL RETAIL SALES, OHIO, 1941- 1943

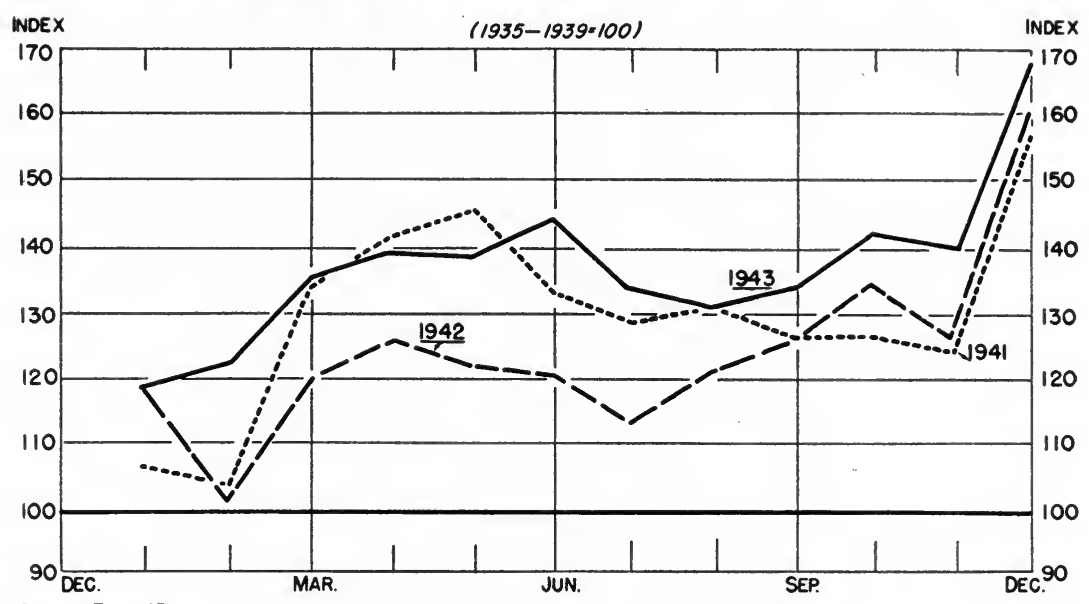

SOURCE: TABLE 15 


\section{CHART I6}

\section{CHART 16 - PER CENT CHANGE IN BUSINESS ACTIVITY, UNITED STATES}

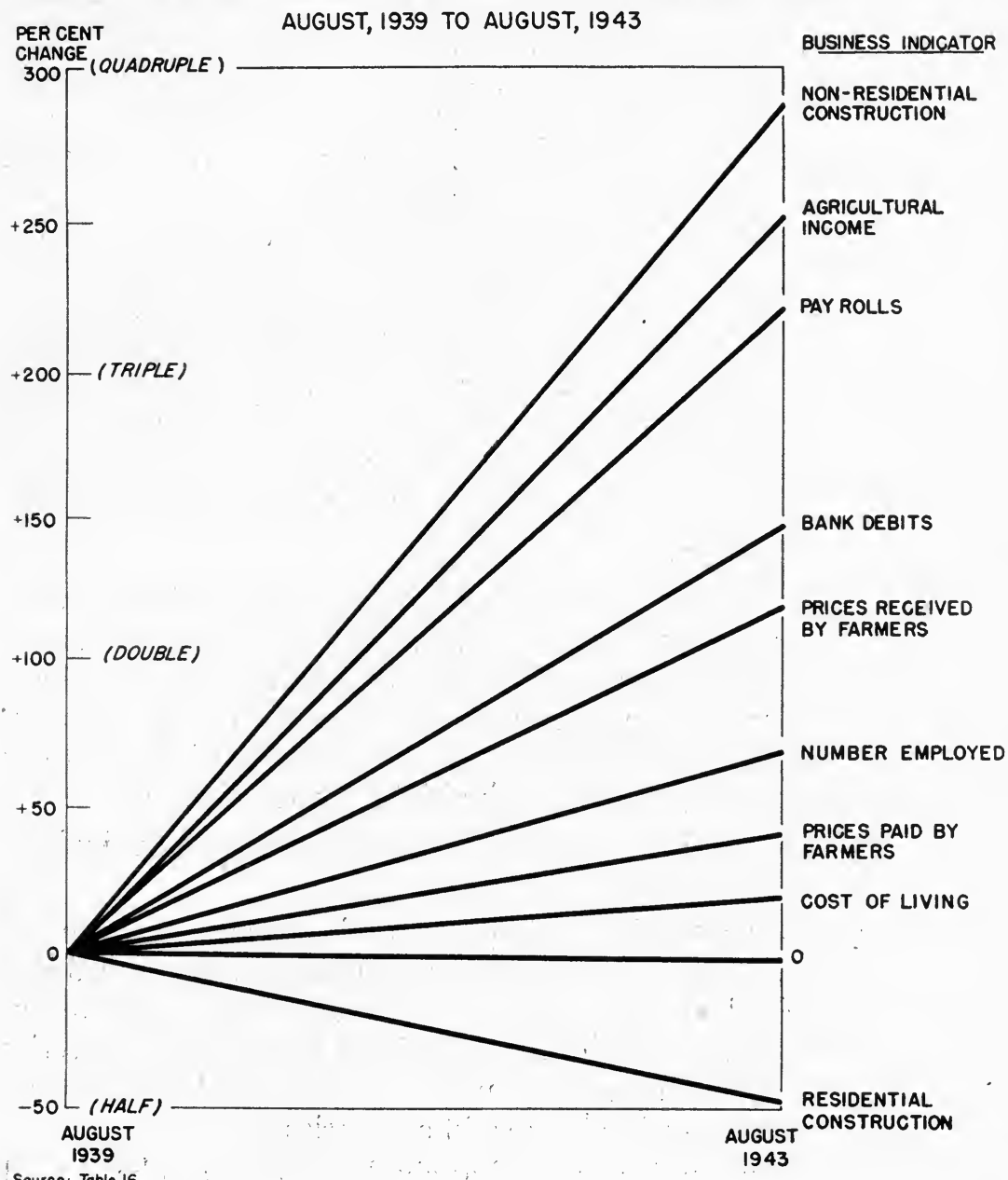

Source: Table 16 
D. Specific rules for logarithmic vertical-scale line-diagram charts (see Chart I7)

I. See rules under VII, A.

2. To emphasize the fact that the data are plotted on a logarithmic scale, put the words "ratio scale" in a prefatory note.

3. In case only one set of scale values is used, the verticalscale numerals should always be at the left of the grid along the vertical axis but may be at both the left and the right. If two different sets of vertical scales are used (very often the case), one scale can be on the left of the grid for one or more curves and another scale on the right for another curve, or other curves.

a. Series in different units may be plotted on this type of chart: For example, one series in dollars and another in persons, or one series showing the volume of sales and another series showing the number of stores. In such cases, one set of vertical scale values would be at the left margin of the grid and the other at the right margin.

4. Since a log scale has no zero line and no line of reference for the plotted values, none of the scale lines are emphasized, and the grid should start with the scale value that represents the lower limit of the numbers plotted and finish with a scale value that is equal to or slightly greater than the highest value charted.

5. The curve label should be placed in the grid field whenever practical.

6. Because of the scaling on semi-log charts, the slope of the curve and not the distance from the bottom grid line should be read. Also, the rate rather than the amount of change should be read. For these reasons, two series in different statistical units can be plotted on the same chart and still allow valid comparisons.

7. Index numbers as well as absolute values can be plotted on a semi-log scale because the slope of the line will be the same whether the given series be in absolute numbers or index numbers. 


\section{CHART I7}

CHART 17 VALUE OF PRODUCTS MANUFACTURED AND NUMBER OF WAGE EARNERS EMPLOYED IN MANUFACTURING, OHIO, BIENNIALLY, 19I9 - 1937

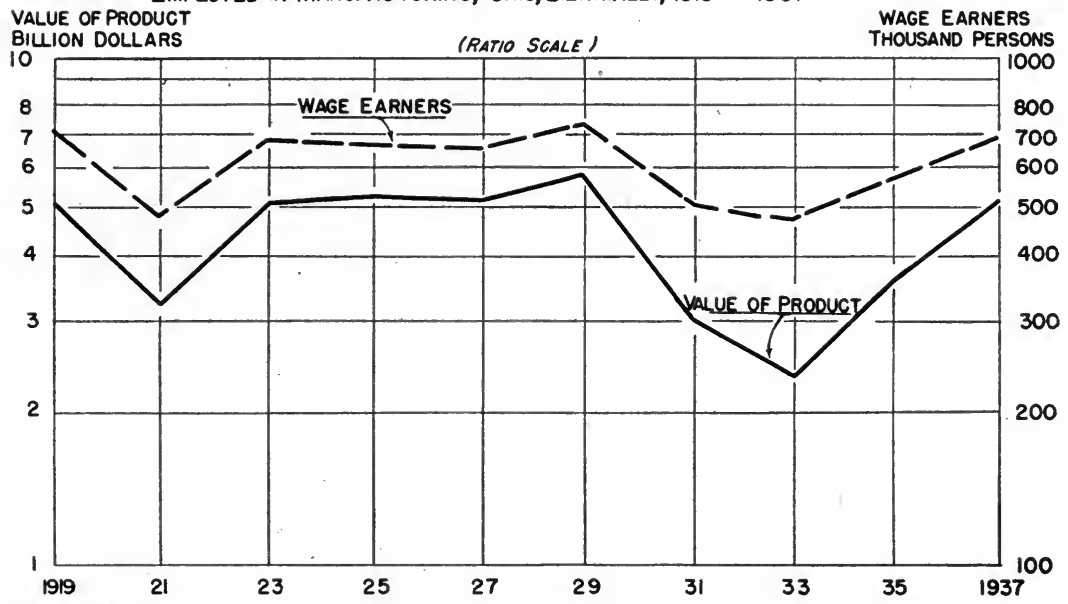

SQURCE: TABLE 17 


\section{GRAPHIC REPRESENTATION OF QUALITATIVE OR QUANTITATIVE CLASSIFICATION BY MEANS OF THREE-DIMENSIONAL CHARTS}

A. Specific rules for any type of three-dimensional chart (i.e., a chart which attempts to show depth)

I. See rules under I.

2. This type of representation should usually be restricted to bar charts, pie-diagrams or pictorial charts.

3. Each bar, circle or symbol is given depth by the use of the third dimension.

4. The third dimension (depth) is used to improve the appearance of the chart and thus to draw more attention to the chart and not to represent values of a third variable. Even though three dimensions are used, only two variables are plotted, one along the vertical axis and the other along the horizontal axis. Objections might be raised to the use of three dimensions to plot two variables, but such objections are of theoretical significance, not of practical importance.

B. Specific rules for three-dimensional bar charts (see Chart I8)

I. The rules II or III for simple bar charts and IV or V for component bar charts should be adhered to in addition to rules under VIII, A.

2. Graphic liberties which are sometimes justified (see Chart I8).

a. The key, as well as the explanation of the data plotted, may be placed in the chart proper as in Chart I8. Thus, an attempt is made to combine the exactness of a table with the advantages of the chart form of presentation. The danger in this practice lies in the fact that visions may be distorted or attention diverted from the trends or magnitudes which alone justify the existence of the chart.

C. Specific rules for three dimensional pie-diagram charts (see page 46) 


\section{CHART I8}

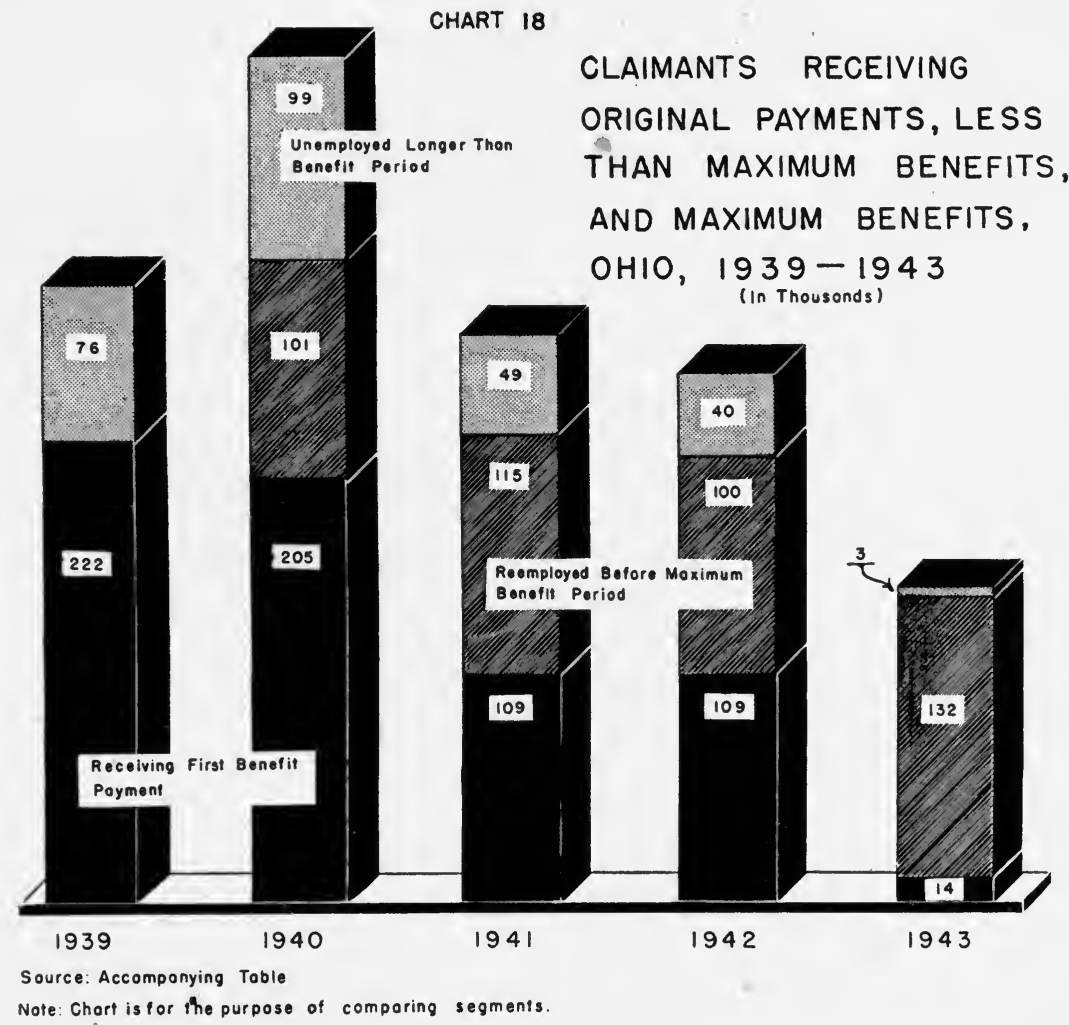


C. Specific rules for three-dimensional pie-diagram charts (see Chart I9)

I. See rules under VI.

2. Graphic liberties which are sometimes justified (see Chart 19).

a. The key, as well as the explanation of the data plotted, may be placed in the chart proper. This practice should be avoided, see VIII, B, 2 (a) above for reason.

b. Sections of the circle may be lifted out for purposes of emphasis. 


\section{CHART I9}

\section{CHART 19 \\ DISTRIBUTION OF THE UNEMPLOYMENT COMPENSATION CONTRIBUTIONS, OHIO, 1939 AND 1943}

41 Cents of Each Dollar

Collected Wos Spent

for Compensotion

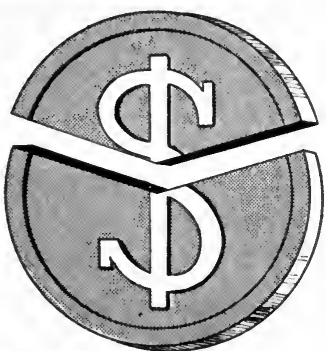

59 Cents to the Fund

1939
2 Cents of Eoch Dollor Collected Wos Spent

for. Compensotion

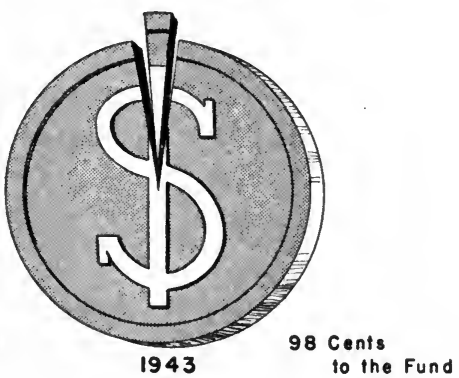


IX.GRAPHIC REPRESENTATION OF STATISTICAL DATA BY MEANS OF PICTORIAL CHARTS

A. Specific rules for any type of pictorial chart (i.e., any chart which uses symbols instead of simply lines and areas) (see Charts 20 and $20 \mathrm{~A}$ )

I. The danger in the use of symbols instead of lines and areas is that too much interpretation of a subjective nature can be imposed on the reader by the type of symbol used to represent the data, and by the manner in which the symbol is constructed. To illustrate, the interpretation of the symbol in Chart 20 might be, and was as a matter of fact, that the persons looked as though they were ready for the grave instead of unemployment compensation. This danger can be minimized by constructing the symbols as mere outlines with little detail.

2. See rules under I.

3. No scale values or lines are used.

4. Larger quantities are shown, not by larger symbols, but by a greater number of symbols.

5. The symbols are placed (drawn) horizontally one next to the other. If data are shown by years, place the data for the earliest year on the top horizontal row followed by the data for the next year, etc. This arrangement for time or other quantitative series, time or quantity on the vertical axis, is out of accord with the general rule that the time and quantity scale be placed along the horizontal axis, and the advantages of reading the series from left to right are lost. Hence, pictorial charts are most effective if the classification is qualitative (see Chart $20 \mathrm{~A}$ ) rather than quantitative or time series.

6. The value assigned to each symbol and the explanation of each symbol is noted at the bottom of the chart.

7. For uniformity of the symbol, a stencil can be made of the symbol and traced on the chart.

B. Specific rules for pictorial three-dimensional pie-diagram charts (see Chart 19)

I. See rules under VIII, C and IX, A.

2. Each symbol represents the total involved in a type of transaction, that is, each symbol represents roo per cent.

C. Specific rules for pictorial bar charts (see page 50) 
PICTORIAL CHARTS

49

CHART 20

CHART 20

AVERAGE WEEKLY NUMBER OF BENEFIT RECIPIENTS, OHIO, 1940 AND 1943

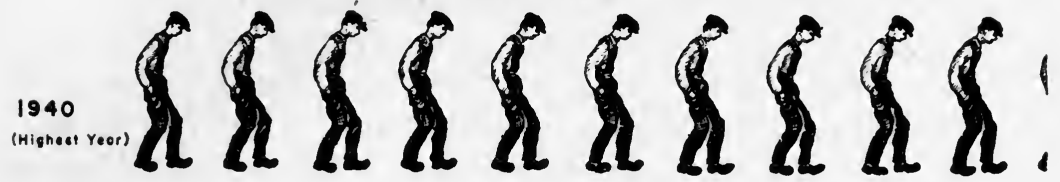

1943

(Lowest Your)

Each Mon Represents 5000 Weeks of Unemployment Compensated Source Accompanying Table

CHART 20A

CHART ZOA - RETAIL SALES, BY MAJOR BUSINESS GROUP, OHIO, 1944

KIND OF BUSINESS

FOOD

GENERAL MERCHANOSE EATING

AND DRINKING PLACE

APPAREL

FILING STATIONS

DRUG, CIGAR

AND NEWS STORE

AUTOMOTIVE

LUMBER-BULDING

FURNITURE-

HOUSE HOLD-RADIO

GENERAL STORES

AND FARM SUPPLIES

HARDWARE

JEWELRY

FLORISTS
SALES VOLUME

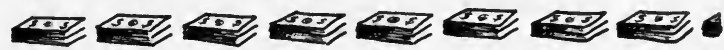

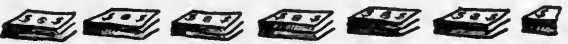

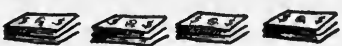

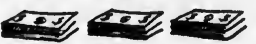

ब्श स्प

क्ष

स्यु

बख्य

क्व

$\Leftrightarrow$

एक्य

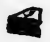

Represents 100 Million Dollars

Source: Table 20 A 
C. Specific rules for pictorial bar charts (see Charts 2I and 2I A)

I. See rules under III for simple horizontal-bar chart, and under $\mathrm{V}$ for component horizontal-bar chart.

2. Symbols (traced from a stencil) may be placed in the , bars primarily to attract attention to the chart but should be so constructed that proper comparison can be made from the symbols as well as from the length of the bar (see Chart 2I).

3. Symbols may be placed to the left of the bar designaCHART 2I

CHART 2I-PERCENTAGE DISTRIBUTION OF. THE VALUE OF MAJOR WAR SUPPLY CONTRACTS, OHIO, MICHIGAN, AND IUNOIS, JUNE, 1940 THROUGH JULY, 1944

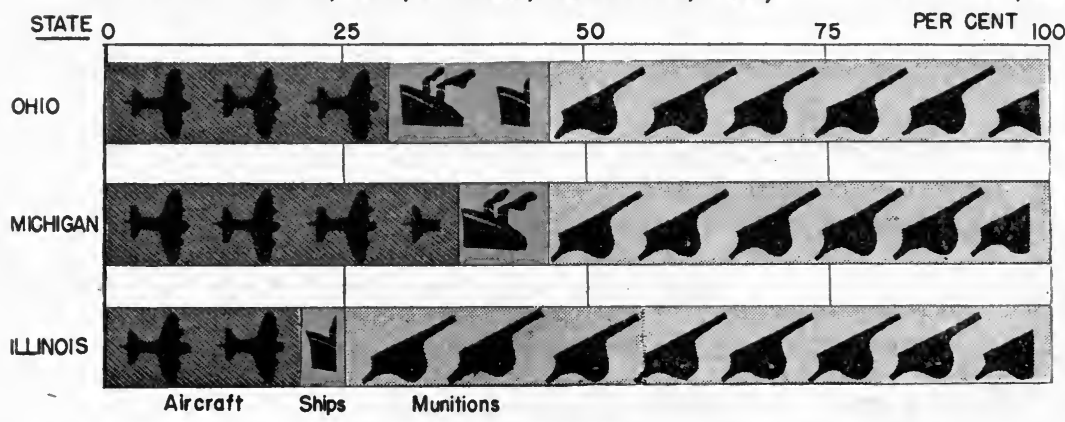

Source: Toble 21

Note: Eoch Symbol Represent 10 Per Cent of the Tolol Volue

\section{CHART 22}

CHART 22 - INDEX OF THE NUMBER EMPLOYED IN THE FOOD

PRODUCT INDUSTRY, OHIO, 1927-1943

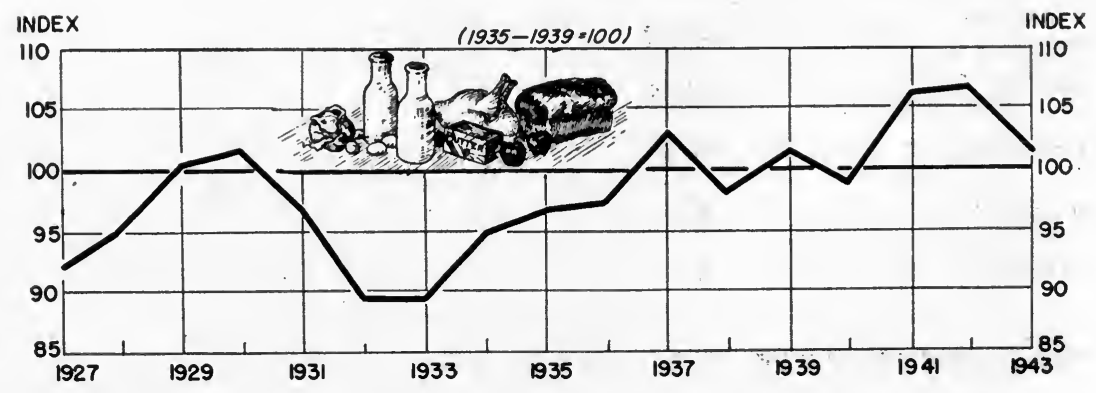


tions for the sole purpose of making the chart more attractive (see Chart $2 \mathrm{I} \mathrm{A}$ ).

D. Specific rules for pictorial line-diagram charts (see Chart 22)

I. See rules under VII, B, C, or D, depending on the scales to be used.

2. Symbols are placed along the lines or in the grid field and should be for no other purpose than to attract attention to the chart.

\section{CHART 2IA}

CHART 2IA- PER CENT CHANGE IN RETAIL SALES, BY, TYPE OF BUSINESS, OHIO, 1944 FROM 1939

KIND OF BUSINESS

PERCENT CHANGE
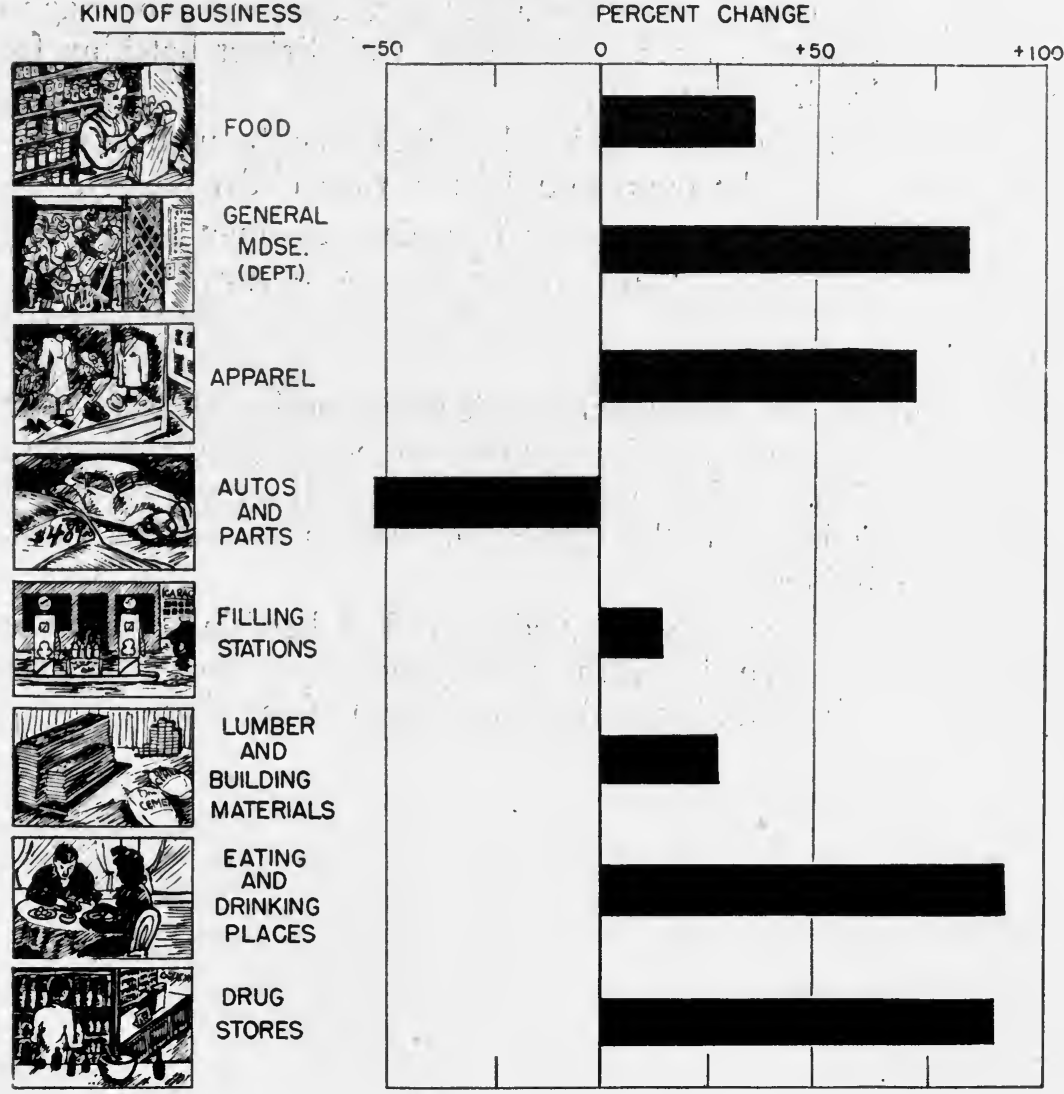

AUTOS
AND
PARTS :
FILLING :
STATIONS
LUMBER
AND
BUILDING
MATERIALS
EATING
AND
DRINKING
PLACES
DRUG
STORES




\section{X.GRAPHIC REPRESENTATION OF STATISTICAL} DATA BY MEANS OF MAPS

A. Specific rules for any type (see Chart 23)

I. See rules under I.

2. Standard outline maps should be used.

3. Only that amount of detail which aids in interpreting the data should be included in the map.

4. No scale values or lines are needed.

5. Writing and putting any numerical data in the map should be avoided.

6. Hatching (shading) should be such that the darkest is used for the most important part as measured by magnitude or on some other basis with lighter hatching for less important parts.

a. Symbols, instead of hatching, may be used on maps to indicate magnitudes (see rules under IX, A).

b. Bar charts, or even line diagrams may be superimposed on maps. Avoid this type of graphic presentation because it tends to become too complicated to interpret.

7. The key consists of sample blocks of the hatchings used, each followed by a statement of its specific meaning. The sample blocks which make up the key should be in series from the darkest at the left or bottom to the lightest.

a. If symbols are used instead of hatchings, the value assigned to each symbol and the explanation of each symbol is noted at the bottom of the chart. 


\section{CHART 23}

Chart 23-Change In Civilian Population Of Ohio Counties, April, 1940 To November, 1943

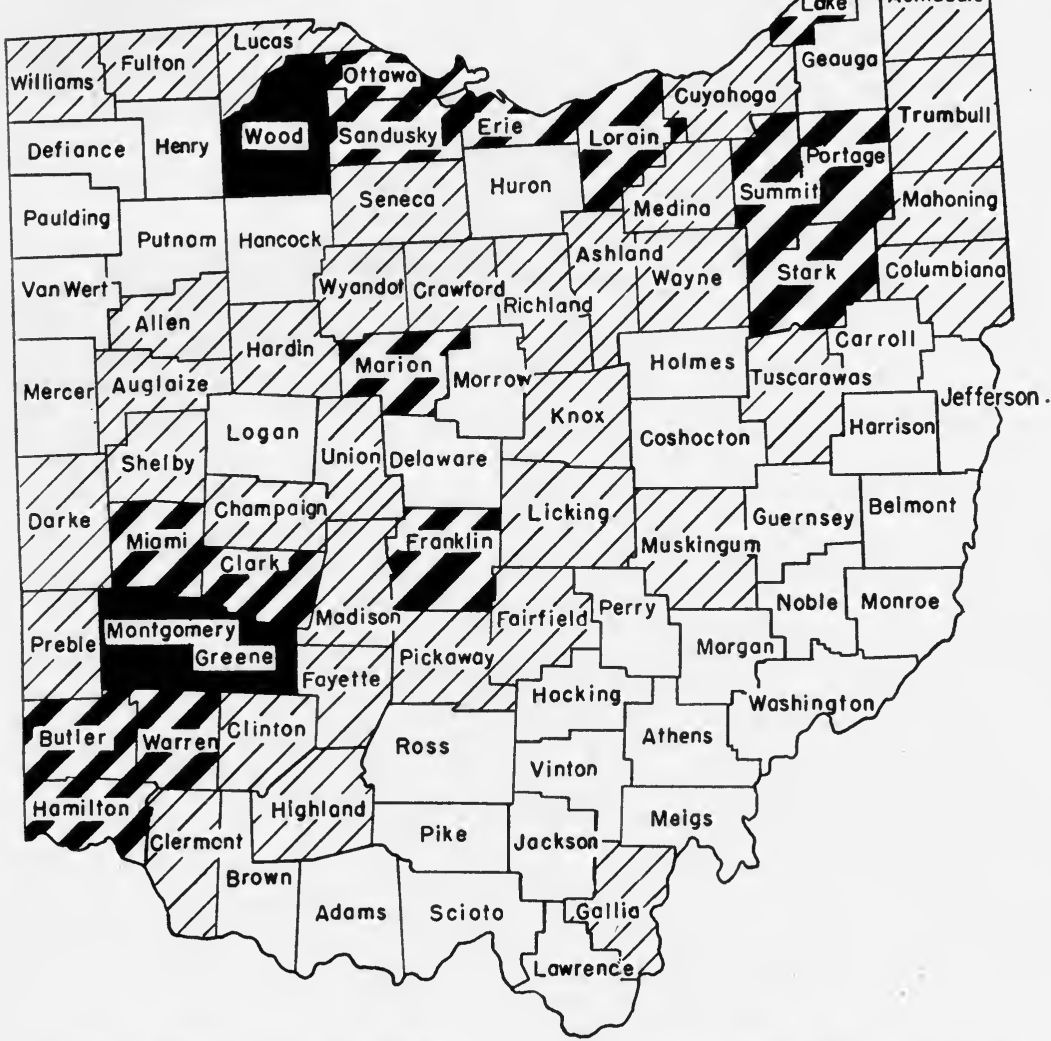

Counties With Increase

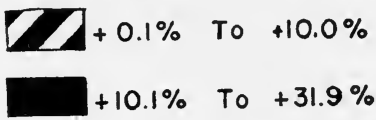

Source: Table 23
Counties With Decrease

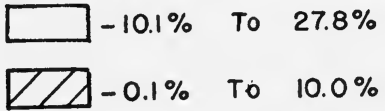


. 


\section{PART II}

EXAMPLES OF CHARTS TO FIT VARIOUS SIZE PUBLICATIONS 
- 


\section{PART II \\ EXAMPLES OF CHARTS TO FIT \\ VARIOUS SIZE PUBLICATIONS}

Charts 24-40 presented in this section are charts which have been used by the Bureau of Business Research, The Ohio State University, in its various publications. These charts serve as examples of charts which can be used to advantage in presenting different types of business data, and can also serve as examples of graphs drawn to fit one column of an $81 / 2$ " by. II" page publication; to fit a $6^{\prime \prime}$ by 9 " page publication; and to fit a $61 / 2$ " by $91 / 2$ " page publication. Also, minor suggestions for improving some of the charts (Charts 24-40) have been made and appear along with the charts to which they apply. These suggested changes apply largely to the use of capital and lower case letters and to the relative size of letters. (See footnote $[\mathrm{I}]$, for a summary discussion of the use of capital and lower case letters and the relative size of letters.) As previously indicated, the size of chart before and after reduction, and the size of letters before reduction are indicated in Table A, Appendix A. Also, examples of suggested types of hatching as well as suggested combinations of hatching which can be used for component bar charts, band charts, and pie diagrams are indicated in Exhibit I, Appendix B. 


\section{CHARTS FOR AN 81/2" BY II" PAGE PUBLICATION}

\section{A. Standard-size charts}

(I) Two 20 pica columns with 2 picas between columns.

(a) Charts are either one-column, $3 \frac{5}{16}$ " wide or two-column, $7^{\prime \prime}$ wide.

(b) Size of full printed page, excluding margins, is $7^{\prime \prime}$ by $91 / 2^{\prime \prime}$ or $93 / 8$.

(2) Two I9 pica columns with $1 \frac{1}{2}$ or 2 picas between columns.

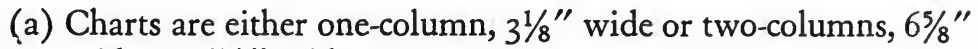
wide or $61 / 2$ " wide.

(b) Size of full printed page, excluding margins, is about $65 / 8$ " or $61 / 2^{\prime \prime}$ by $91 / 2^{\prime \prime}$ or $93 / 8^{\prime \prime}$.

B. Odd-size charts are sometimes desirable. That is to say, for some purposes, it might be of some advantages to make one column of a page wider and, hence, the other column of the page that much narrower. Also it may be of some benefit to leave wider margins than indicated in (I) and (2) above. Examples of these odd-size charts are included along with the other more standard size onecolumn charts. 


\section{CHART 24}

\section{CHART 24-PER CENT CHANGE IN SELECTED BUSINESS INDICATORS UNITED STATES June, 1944 from June, 1943}

BUSINESS INDICATOR
BANK DEBITS
COM. FAILURES (NUMBER)
AGR. INCOME
LIFE INS. SALES
PAY ROLLS MFG.
NO. EMPLOYED MFG.
INDUSTRIAL PROD.
POWER PROD.
COAL PRODUCTION (BIT)
CONST. CONTRACTS
FREIGHT CAR LOADINGS
RETAIL SALES (34 STATES)
DEPT. STORE SALES
CHAIN STORE SALES
WHOLESALE PRICES
RETAIL FOOD PRICES
COST OF LIVING

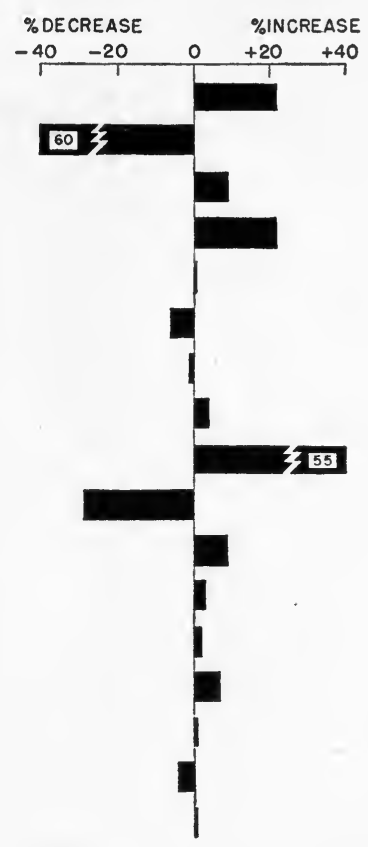

Source: Tab'e 24

Interpretation-Bank debits, that is, bank checks drawn against the accounts of "individuals," were approximately 25 per cent greater in June of I944 compared with June, 1943. The bar indicating the per cent change in commercial failures is broken to caution the reader that the length of the bar is not to be interpreted in terms of the scale indicated on the chart; instead, the value inserted in the bar (6o) indicates the per cent decrease in the number of commercial failures in the United States in. June, r 944 as compared with June, I943.

The comparison of various factors in a given month in one year with the same month in a different year is significant in that this comparison gives an indication of trend, the seasonal factor being ruled out because the same month is used in both years.

Suggested Improvement-The bar descriptions should have been done with a smaller size letter. 


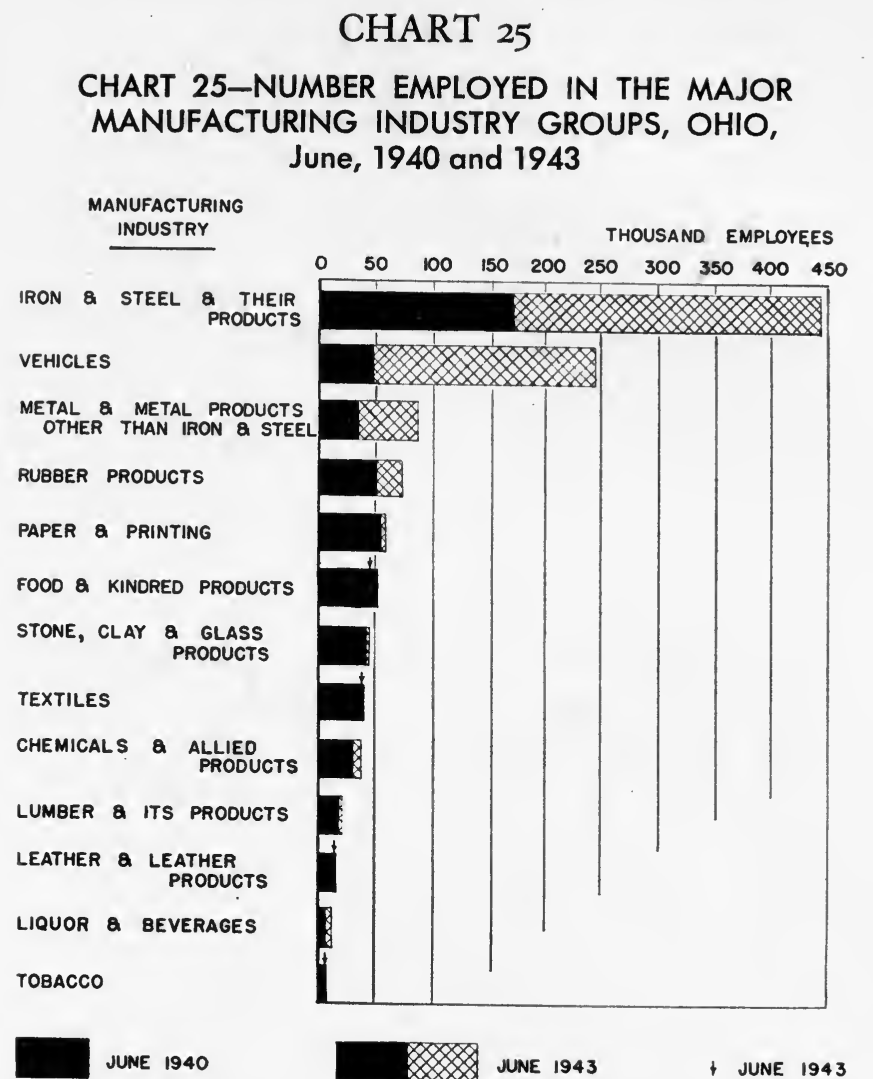

Source: Table 25

Interpretation-Approximately I70 thousand employees were employed in the Iron and Steel Industry in Ohio as of June 1940. The number employed, June, 1943, increased to about 440 thousand employees. Close to 52 thousand were employed in the Food and Kindred Products Industry in Ohio in June, 1940. This number decreased to 49 thousand in June, 1943.

The use of one bar to indicate the condition at two different points of time can be accomplished successfully if the data for the first point of time are less than the data at the second point of time. In this chart the data for the first date (June, 1940) are indicated by the black part of the bar. The data for the second date (June, 1943) are indicated by the full length of the bar. The use of the hatching makes it possible to show the extent of the increase in the latter period.

Suggested Improvement-The key should have been lettered with capitals and lower case to agree with the lettering of the source. 


\section{CHART 26}

\section{CHART 26-SELECTED BUSINESS INDICATORS,OHIO, FIRST HALF 1940-1945}
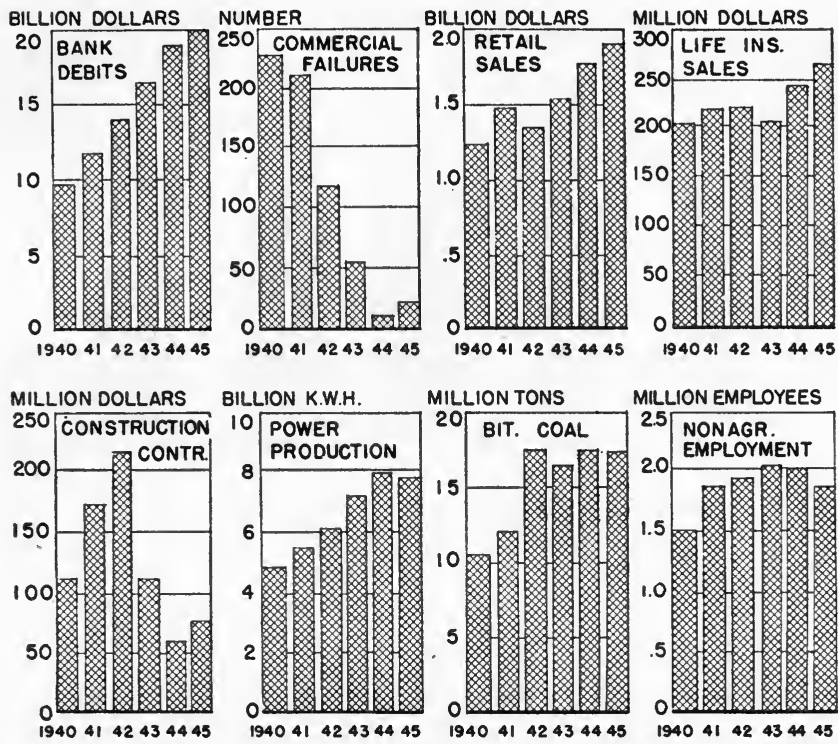

Source: Table 26

Interpretation-Series reflecting the trends in the dollar volume of business and the physical volume of production for Ohio for the first half-years of 1940-1945 are shown in Chart 26.

General business activity as measured by bank debits ( 16 Ohio cities) increased from $\$ 9$ billion for the first half of 1940 to $\$ 20$ billion for the first half of 1945 .

Commercial failures decreased steadily during the five-year period, I940I944, dropping from 230 for the first six months of 1940 to 12 for the same period in 1944. Failures were up to 22 for the first half of 1945 .

Suggested Improvement-Because of space limitations the horizontal numerals (years) had to be done with a smaller size numeral than was used for the vertical scale numerals. A larger size number could have been used if the horizontal numerals for every other year had been omitted. 


\section{CHART 27}

\section{CHART 27-GROSS NATIONAL PRODUCT, BY USE OF PRODUCT, UNITED STATES, 1939-1943}

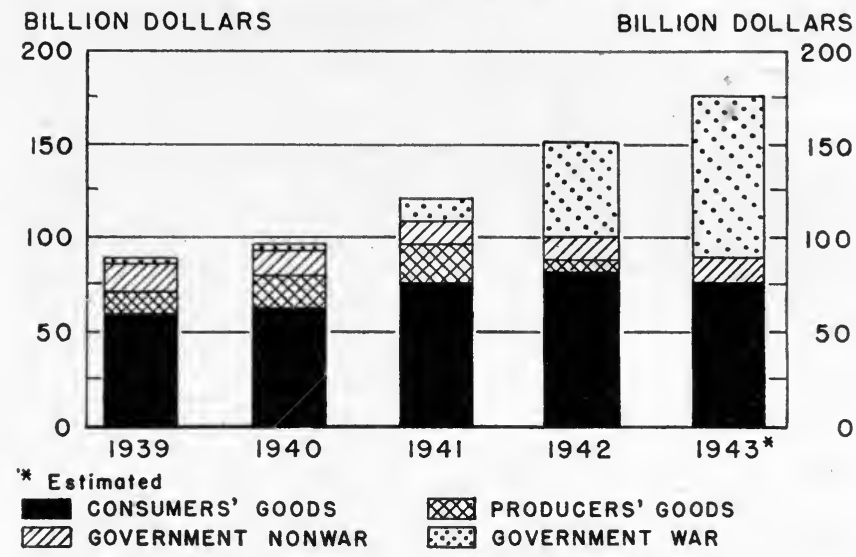

Source: Table 27

Interpretation-Gross national production is a statistic designed to measure, in terms of current dollars, the value of all goods and services produced in an economy. It is the market value of all goods and services produced and sold to final buyers by private industry during a given period, plus the current value of the change in inventories, plus the value of government "output" as measured by government payments to the factors of production.

Gross national production increased from $\$ 88$ billion in the peacetime year of 1939 to about $\$ 152$ billion in 1942 , an increase of about 73 per cent. Throughout the period, I939-1942, dollar expenditures for consumers' goods increased; a slight decrease occurred in 1943. Dollar expenditures by the government in the execution of the war increased throughout the period 1939-1943.

Suggested Improvements-The key should have proceeded from dark to light with the solid black appearing at the lower left. Also, the key should have been lettered with capitals and lower case and with a smaller size letter to agree with the lettering of the footnote and source. 


\section{CHART 28}

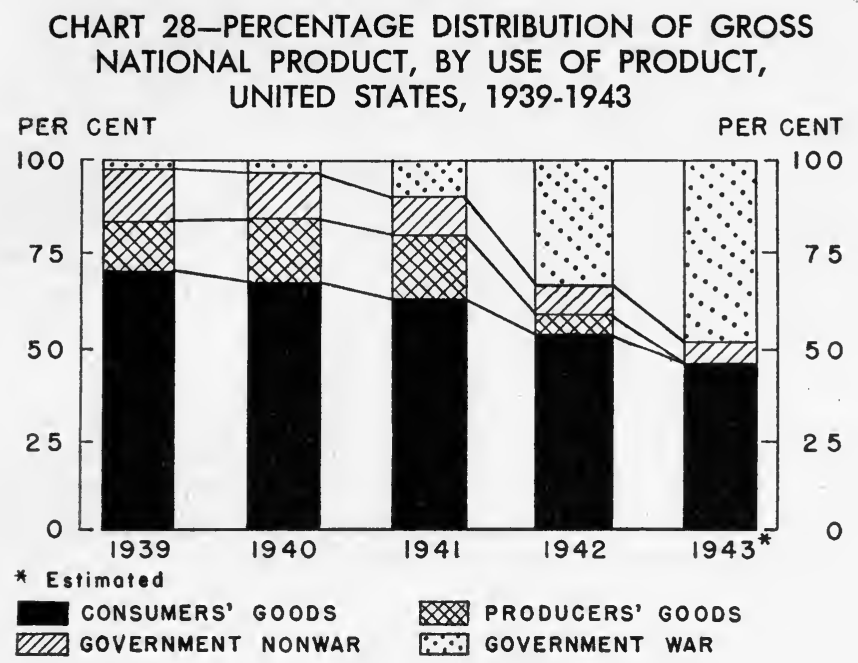

Source: Table 28

Interpretation-The percentage distribution of gross national production reveals significant changes in the pattern of expenditures. The relative importance of the output available for private use decreased from about 83 per cent of the total gross national production in 1939 to about 59 per cent in 1942, and it was estimated that the I943 per cent would be only 45. The war-impact ratio, which roughly reflects the extent to which our home front had been mobilized for war, increased from less than 2 per cent in 1939 to an estimated high of 50 per cent in 1943 .

Suggested Improvements-The key should have proceeded from dark to light with the solid black appearing at the lower left. Also, the key should have been lettered with capitals and lower case, and with a smaller size letter to agree with the lettering of the footnote and the source. 


\section{CHART 29}

Interpretation-The value of contracts awarded for non-residential construction increased over 150 per cent in August, 1942 from August, I939. Pay rolls in manufacturing were up about 140 per cent in August, 1942 as compared with August, 1939. Prices received by farmers increased about 80 per cent by August, 1942 as compared with August, 1939. Prices paid by farmers in August, 1942 were up about 30 per cent from August, 1939.

Suggested Improvement-The bar designations should have all capitals to agree with the lettering in the title. Also, the broken bar, non-residential, should have the numerical value inserted in it. As it now stands, the reader knows only that it is an increase of more than $150 \%$. 


\section{CHART 29}

CHART 29-PER CENT CHANGE IN SELECTED BUSINESS INDICATORS DURING THE FIRST THREE YEARS OF

THE WAR, UNITED STATES, AUGUST,1939 to AUGUST, 1942

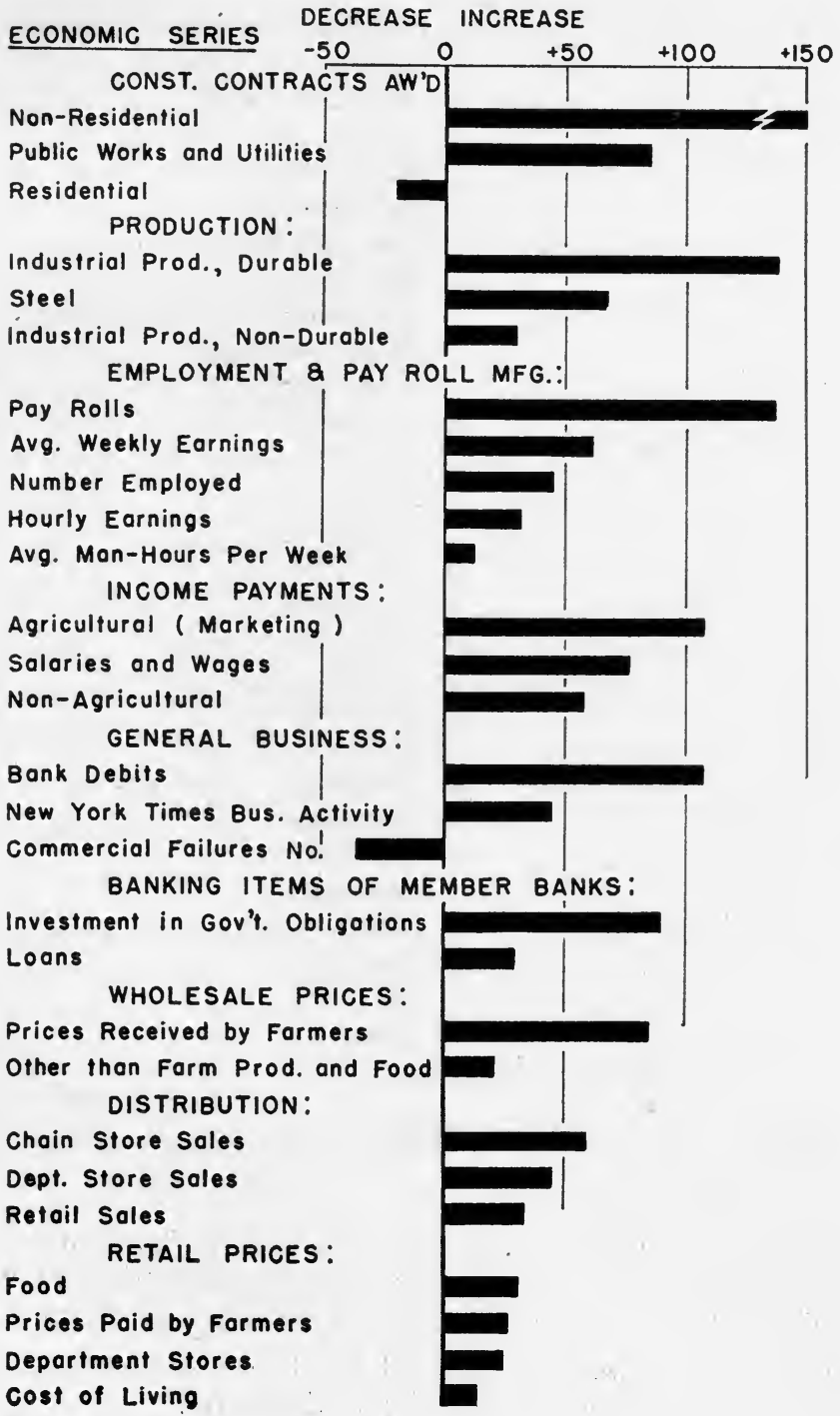

Source: Table 29 


\section{CHART 30}

CHART 30-PER CENT CHANGE IN AVERAGE HOURLY EARNINGS IN PRINCIPAL INDUSTRIES, OHIO, JANUARY, 1941 to SEPTEMBER, 1942 AND 1943

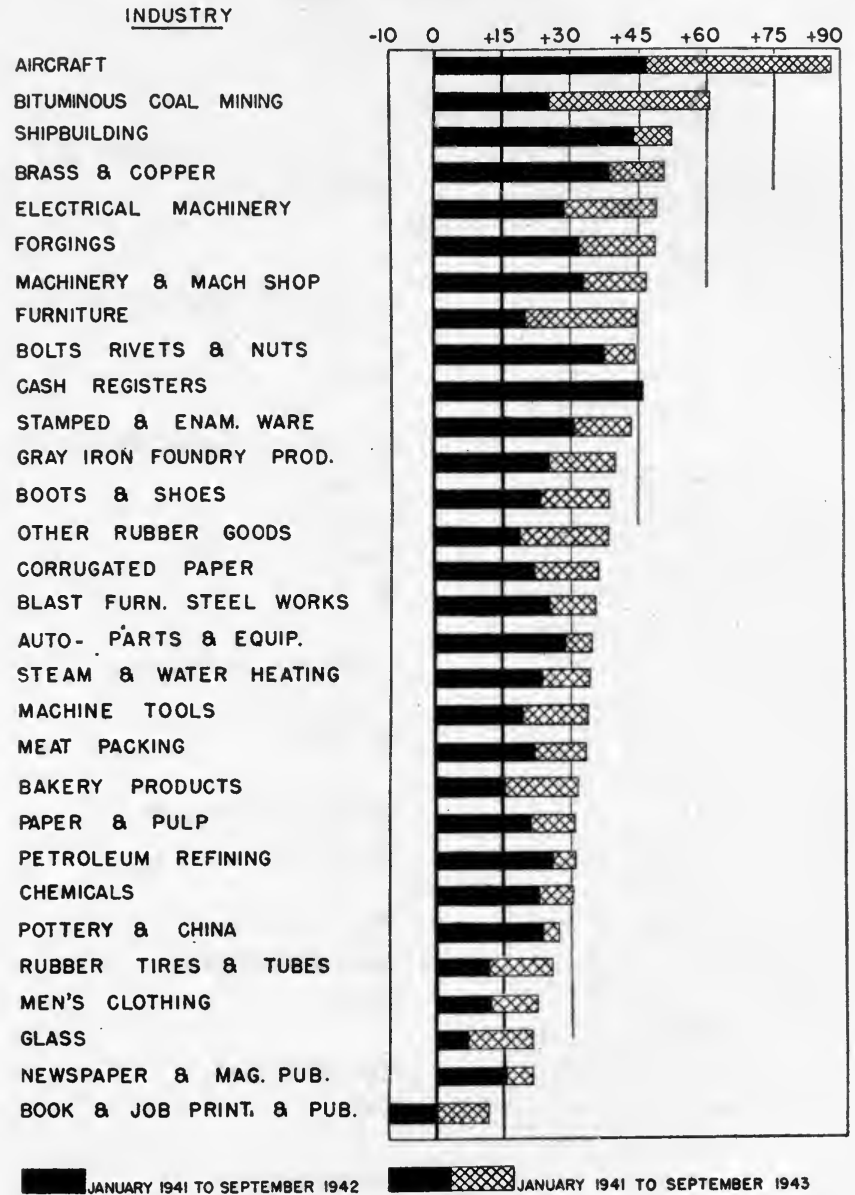

Source: Table 30

Interpretation-Chart 30 indicates the per cent change in the average hourly earnings for wage earners in the 30 leading industries in Ohio for the periods January I94I to September 1942, and January I94I to September I943.

Suggested Improvement-The key should have been lettered with capitals and lower case to agree with the lettering of the source. 


\section{CHART 3 I}

\section{CHART 31-AMOUNT AND PERCENTAGE DISTRIBUTION OF WAR CONTRACTS, BY PURPOSE, SELECTED AREAS, OHIO, JUNE, 1940 - JANUARY, 1944}

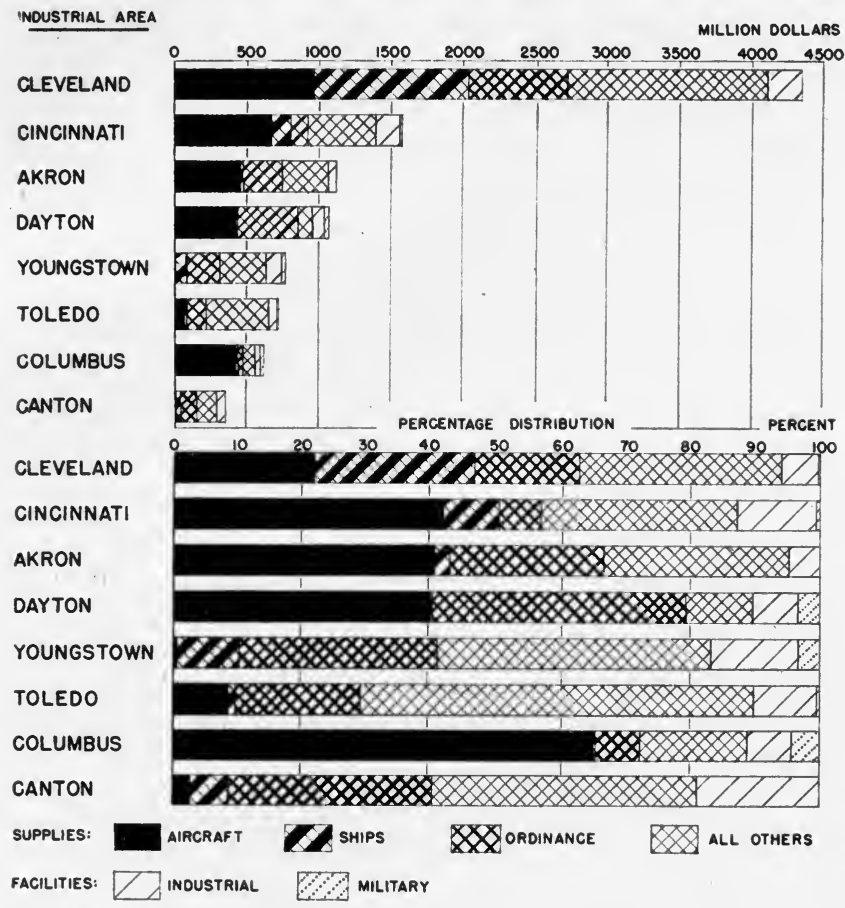

Source: Table 31

Interpretation-Evidence of the large-scale industrial war activity in the 8 large industrial areas in Ohio is amply abundant in the data on the value of war prime contracts for the period June, 1940, through January, 1944, which appear in Chart 31. These data are broken down to show the value of war supply contracts for aircraft, ships, ordnance, and all others, and to show the value of war-facilities projects for industrial. and military purposes. The supply contracts have been assigned to industrial areas on the basis of location of production plants while the facilities contracts have been assigned on the basis of project site.

Suggested Improvements-The scale description as well as the scale numerals and vertical qualitative classification should have been done with a larger size letter similar to that used for the bar description. Also, the key should have been lettered with capitals and lower case to agree with the lettering of the source. 


\section{CHART 32}

\section{CHART 32-WHOLESALE COMMODITY PRICE, UNITED STATES, WORLD WAR I (1914-1918) AND WORLD WAR II (1939-1943)}

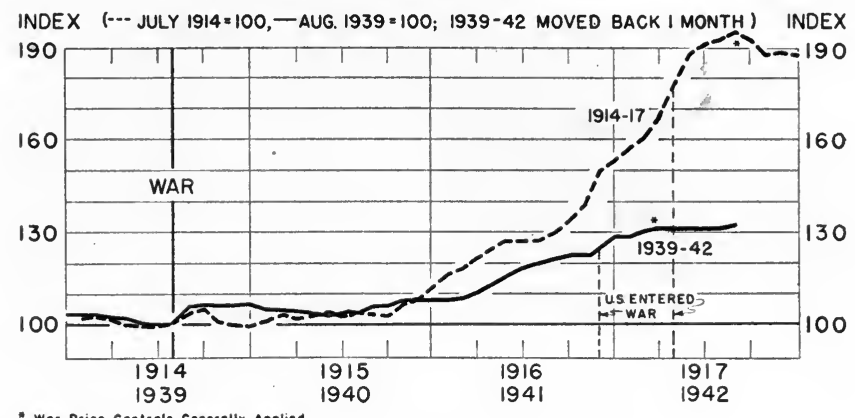

Wer Price Cantrals Generally Apolied

Source: Table 32

Interpretation-Wholesale commodity prices during World War I increased about 80 per cent from the beginning of the war in Europe until formal declaration of war by the United States 33 months later. During World War II, wholesale prices increased about 25 per cent from the time war broke out in Europe until formal declaration of war by the United States, 27 months later.

After 3 years of World War I, wholesale prices were up about 90 per cent while after 3 years of World War II, wholesale prices were up only about 30 per cent.

Suggested Improvements-The prefatory note should have been lettered in capitals and lower case to agree with the lettering of the footnote and source. The footnote should have been done with a larger size letter to agree with the letter size in the prefatory note. 


\section{CHART 33}

\section{CHART 33-SALES AND REDEMPTION OF WAR BONDS, UNITED STATES, MAY, 1941 - APRIL, 1943}

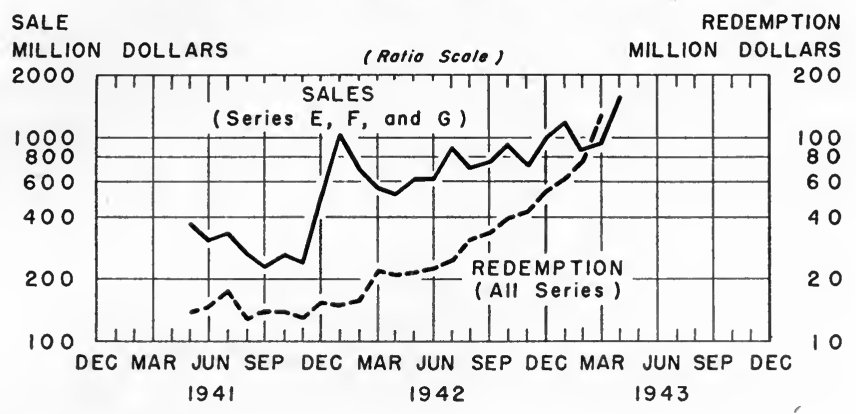

Source: Table 33

Interpretation-The two trend lines indicate, among other things, the rates of change in war bond sales and war bond redemptions. In general, the redemption of war bonds increased at a faster rate than did the sale of war bonds. The sharp increase in the sale of war bonds took place shortly after Pearl Harbor. Other significant increases occurred during war-loan drives.

The sharp increase in the redemption of war bonds in March, 1942 can be accounted for, in large part, by the need for cash to pay income taxes. 


\section{CHART 34}

\section{CHART 34-CORPORATE PROFIT AND NET ADDITION OR REDUCTION IN SURPLUS, UNITED STATES, 1929-1943}

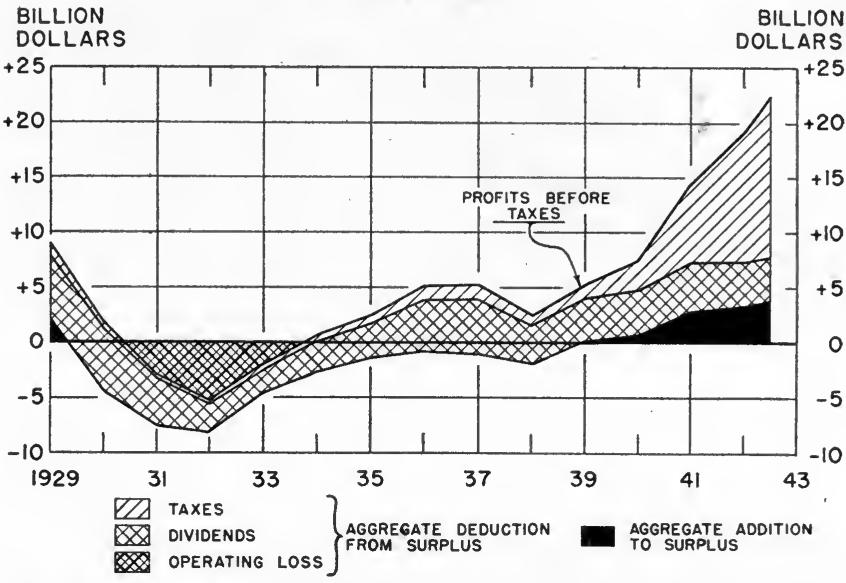

Source: Table 34

Interpretation-Following 1929, more corporations had deficits than profits, hence, for the whole country, no additions to surplus occurred until I940. In I94I and 1942 additions were also made to surplus. In these two years, the largest part of profits was consumed by taxes.

During the years I930-1939 deductions were made from surplus. The largest deductions from surplus occurred in I93 I and 1932. Despite the fact that losses were greater than profits during 1930-1939, considerable amounts were paid in dividends.

Suggested Improvements-The curve label should have been done with a larger size letter similar to that used for the scale description. Also, the key should have been lettered with capitals and lower case to agree with the lettering of the source. 


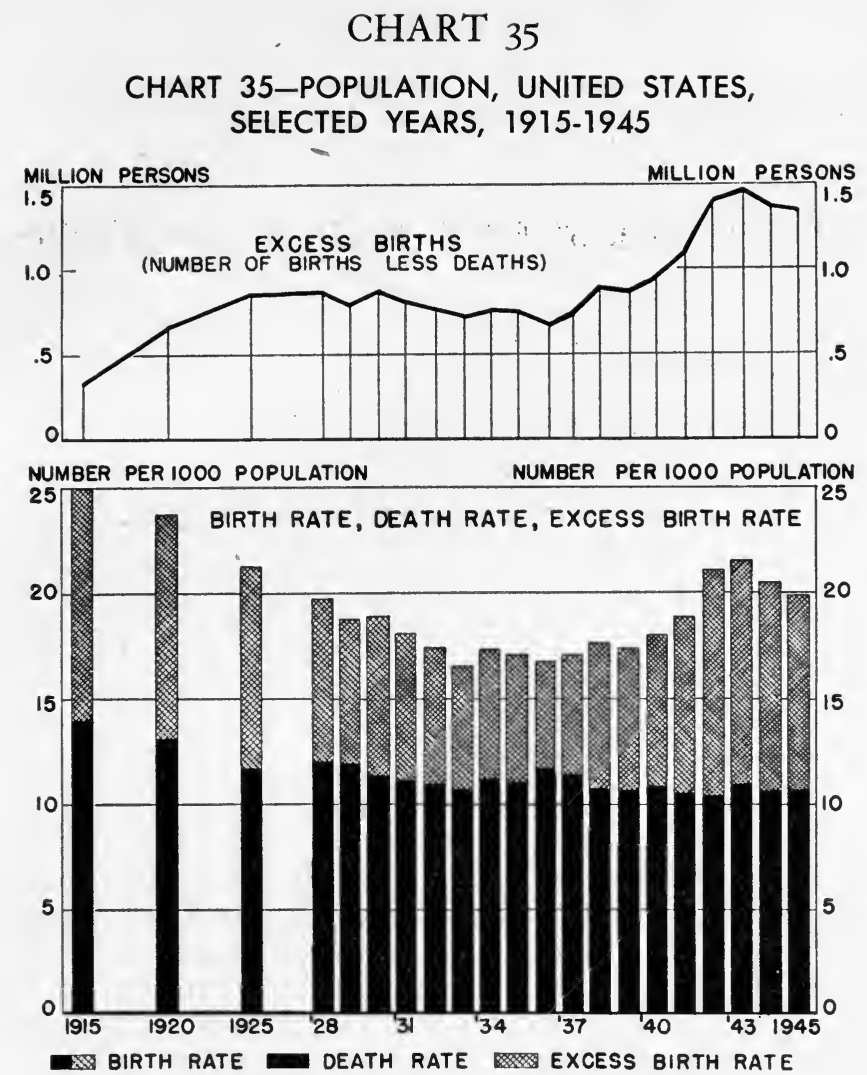

Source: Table 35

Interpretation - The annual increase in the population went from 340,000 in 1915 to a high of 882,000 in 1930 . After I930 population increases were less each year and by 1936 the population increase was down to 666,000. Following 1936, population increased by a greater amount each year, except 1939, and by 1943 the increase of I,475,000 persons represented an all-time high. Population increased I,383,000 in 1944 and $1,347,000$ in 1945.

The five-year wave of high birth rates will be felt all along the line as it travels through the future years. At first, suppliers of baby goods will feel the impact on the demand for their products. Educational facilities will be pushed to take care of the increased load-first the elementary schools, then the high schools. Colleges will probably also be hit by the bulge some fifteen years hence. The five-year birth boom will subsequently result in an unusual increase in the labor supply which will have its effect on the labor market. Changes in the population age structure as a result of these high birth-rate years will have their effects on problems of old-age insurance. 


\section{CHARTS FOR 6" BY 9" PAGE PUBLICATION}

A. Standard size charts

(I) One 25 or 26 pica column about $4 \frac{1 / 8}{11}$ wide.

(a) Charts are $4 \frac{1 / 8}{8}$ wide.

(b) Size of full printed page, excluding margins, is $4^{1 / 8^{\prime \prime}}$ by $7^{\prime \prime}$.

\section{CHART 36}

Interpretation-With the complete employment records of employees in a selected number of Ohio companies, for the period 1928-1932, estimates were made of the total wage-loss resulting from unemployment of the employees. The amount of benefits which would have been paid to the employees under the benefits provisions of the 1938 New York law, Wisconsin law, and Ohio law were estimated and related as a per cent of the wage-loss.

Thus, if the Ohio and New York unemployment compensation laws, with their 1938 provisions, had been in effect in I 928 through I932, the amount of lost wages replaced by benefits would have been less than 9 per cent, or only $\$ \mathrm{I}$ for every $\$ \mathrm{II}$; and the Wisconsin law was even less liberal-about \$I for every $\$$ I 8 . 


\section{CHART 36}

CHART 36-WAGE LOSS REPLACED BY BENEFITS UNDER THE ORIGINAL (1938) OHIO, WISCONSIN, AND NEW YORK LAWS, 13 COMPANIES, OHIO, 1928-1932

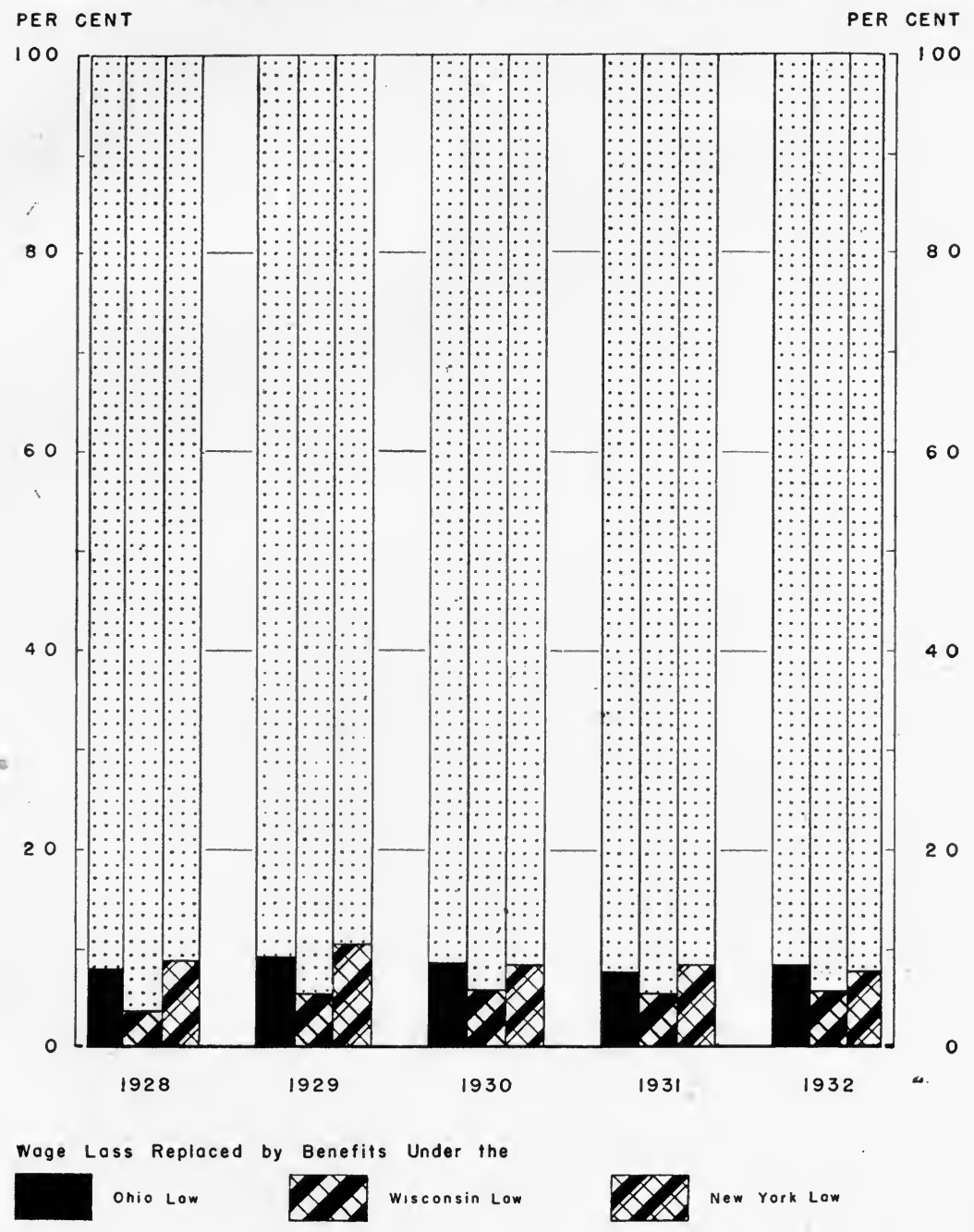

Wage Lass not Replaced by Benefits Under the

$\because: \because::$ onio-wisconsn-New York Lows

Source: Table 36 


\section{CHART 37}

Interpretation-Based on the employment experience of employees in selected Ohio companies during 1928-1932, the amount of wage-loss replaced by benefits, under the provisions of the 1938 Ohio law, would have been about 9 per cent. The amount of wage-loss replaced by benefits, under the $194 \mathrm{I}$ amended Ohio law, would have been about II per cent. Thus, the Ohio law was liberalized in I94I, as far as benefits are concerned, by about 20 per cent. 


\section{CHART 37}

CHART 37-WAGE LOSS REPLACED BY BENEFITS UNDER THE ORIGINAL OHIO AND UNDER 1941 AMENDED OHIO LAWS, 13 COMPANIES, OHIO, 1928-1932

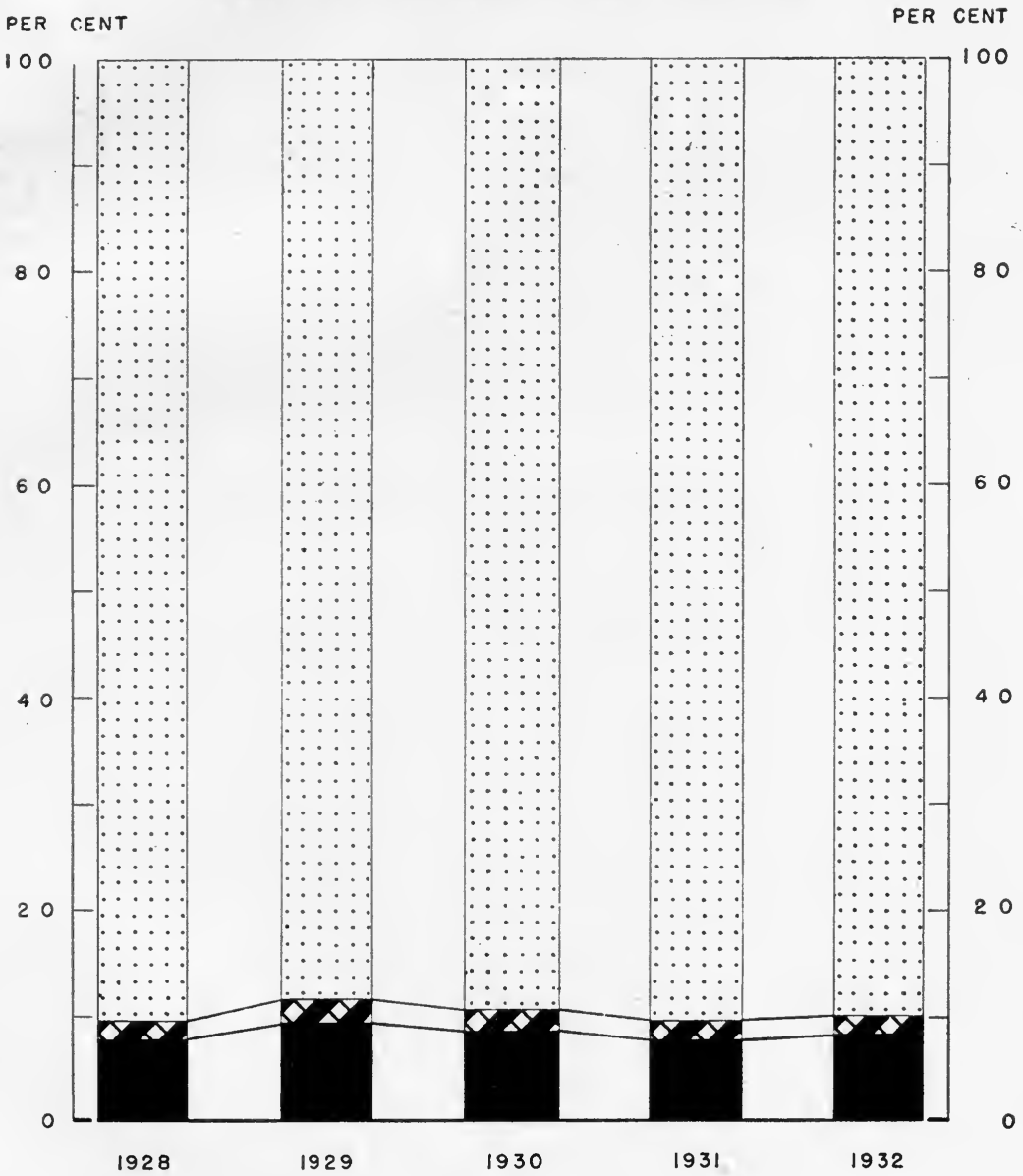

Wage Loss Replaced by Benefits Under the

ss not Replaced by

Benefits

Under the 


\section{CHART 38}

Interpretation-Of the total number of male unemployment-compensation beneficiaries during 1939-1940, about 32 per cent were skilled workers, 24 per cent were semi-skilled, Io per cent were unskilled while about 27 per cent were low-salaried workers. The professional and managerial group represented about 5 per cent of the total.

The distribution of the female unemployment-compensation beneficiaries was materially different. Of the total, about 65 per cent were low-salaried workers, slightly over I4 per cent were semi-skilled workers and about ro per cent were unskilled. Only 2 per cent were from the professional and managerial group.

Suggested Improvements-The scale description should have been done with all capitals to agree with the lettering of the vertical qualitative classification. The bottom scale lines could have been omitted without damage to the chart. Also, the key should have been done with a smaller size letter and in capitals and lower case letters to agree with that of the source. 


\section{CHART 38}

\section{CHART 38-PERCENTAGE DISTRIBUTION OF MEN AND WOMEN} BENEFICIARIES, BY OCCUPATION GROUPS, COLUMBUS, OHIO, 1939-1940

SEX

Per Cent
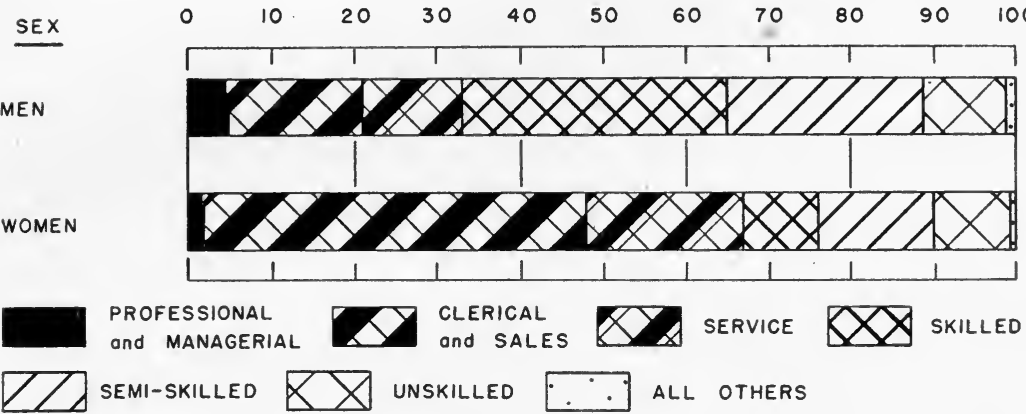

PROFESSIONAL

and MANAGERIAL

CLERICAL and SALES

SERVICE SKILLED

Source: Table 37

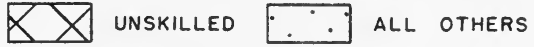

SEMI-SKILLED $\triangle$ ALL OTHERS 


\section{CHART 39}

Interpretation-Dovetailing of seasonal employment between companies has long been of both academic as well as practical significance.

Dovetailing of seasonal employment has been and can be used as a means of eliminating seasonal unemployment of the worker.

The best dovetailing possibilities in Cuyahoga County appear to be between the Dairy Industry and: first, Ship and Boat Yards; second, Stoves and Furnaces; third, Confectionery; and fourth, Yards: Lumber and Scrap.

Suggested Improvements-The scale description as well as the scale numerals should have been done with a larger size letter. Also, the scale description (designation) should have been done with all capitals to agree with the lettering in the title. 


\section{CHART 39}

CHART 39-INDEXES OF SEASONAL EMPLOYMENT OF WAGE EARNERS IN THE DAIRY PRODUCTS AND ICE CREAM INDUSTRY AND IN INDUSTRIES WITH COMPLEMENTARY SEASONAL PATTERN, CUYAHOGA COUNTY, OHIO, 1926-1936
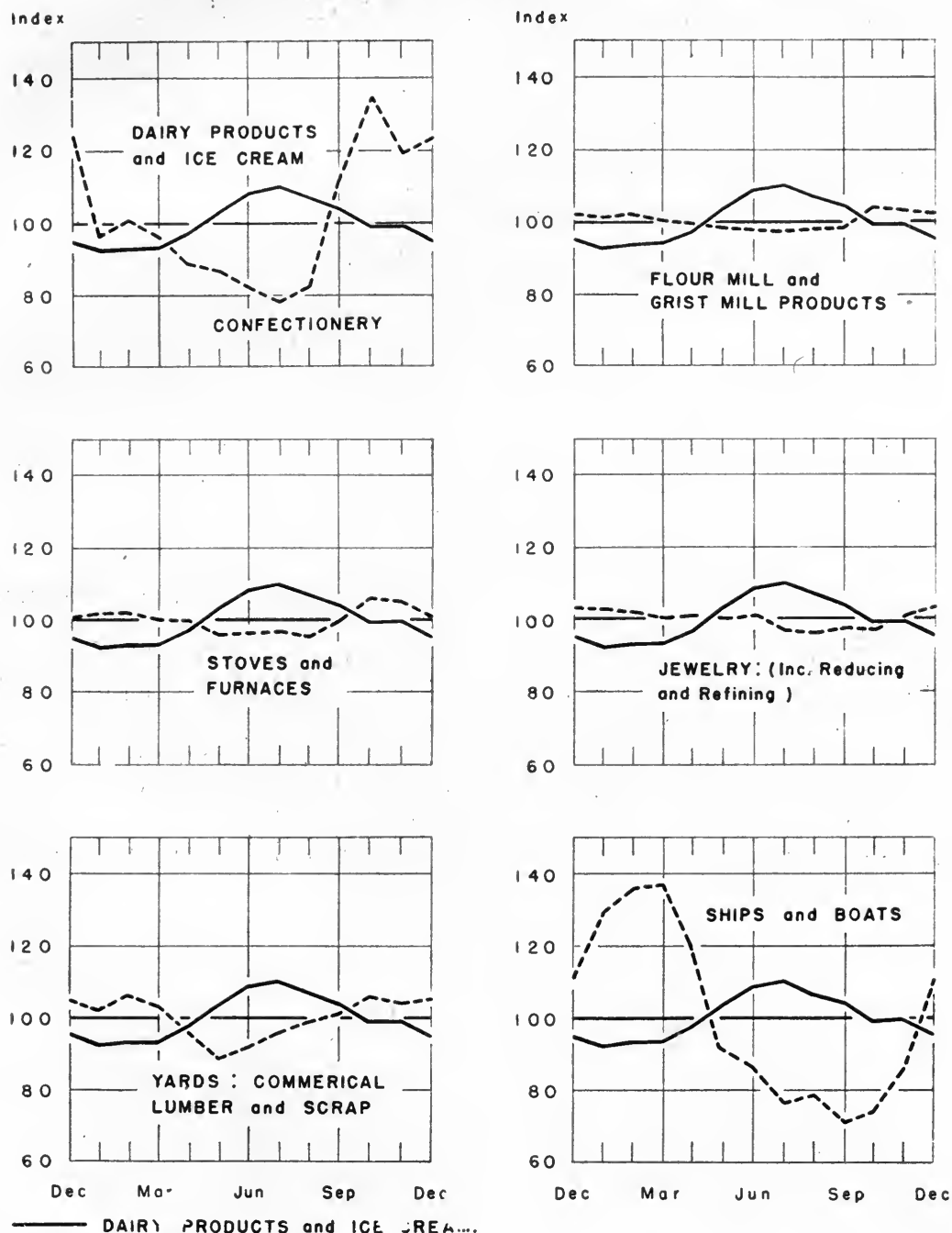

Source: Table 39 


\section{CHARTS FOR A 61/2" BY 91/2" PAGE PUBLICATION}

A. Standard size charts

(I) One 26 or 27 pica column about $4 \frac{1 / 4}{\prime \prime}$ wide.

(a) Charts are $4^{1 / 4} 4^{\prime \prime}$ wide.

(b) Size of full printed page, excluding margins, is $4^{1 / 4^{\prime \prime}}$ by $7^{\prime \prime}$.

\section{CHART 40}

Interpretation-Absolute as well as relative changes in the physical volume of manufactured goods were materially greater than those in the physical volume of minerals produced over the period 1935-1943. After the war began in Europe, 1939, the quantity of goods manufactured increased significantly while the quantity of minerals produced registered relatively minor increases. The greatest increase in the quantity of goods manufactured occurred in the production of durable goods which were used primarily for war purposes after I94I. The portion of nondurable goods used by civilians during the war period was well above the 1932 level but slightly less than the I 929 level. 


\section{CHART 40}

CHART 40-INDEXES OF PHYSICAL VOLUME OF PRODUCTION OF MANUFACTURES AND MINERALS ADJUSTED FOR SEASONAL

VARIATION, UNITED STATES, 1935-1943

(RATIO SCALE)

INDEX

$1935-39=100$

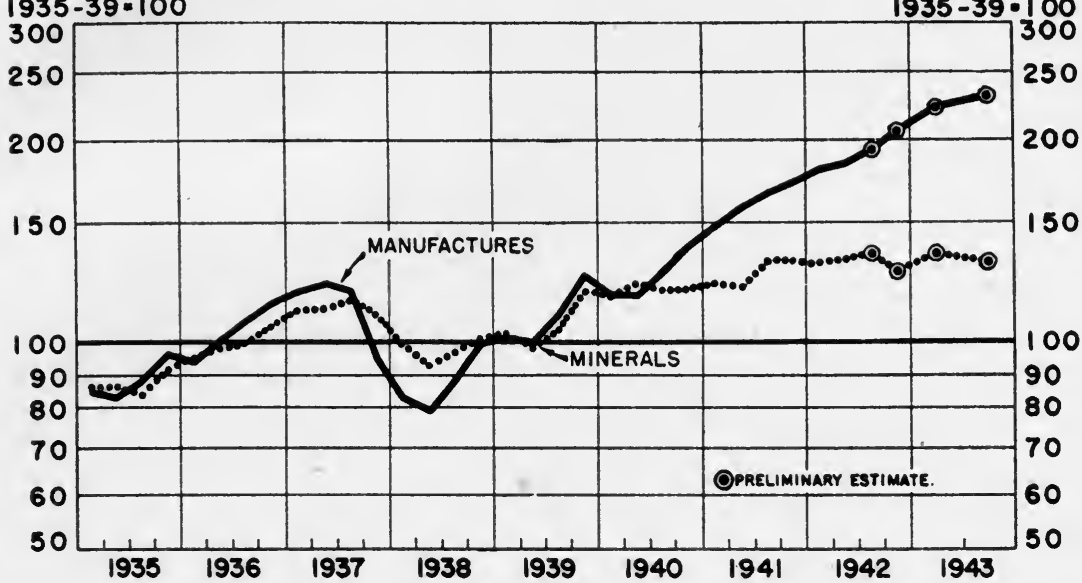

INDEX

$1935-39 \cdot 100$

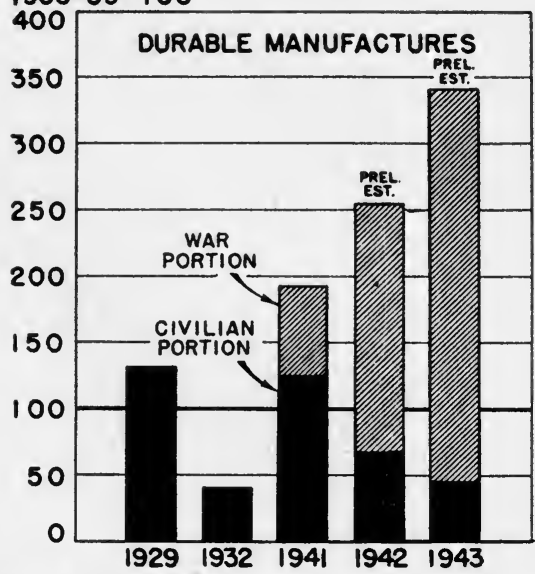

Source: Table 40

INDEX

$1935-39=100$

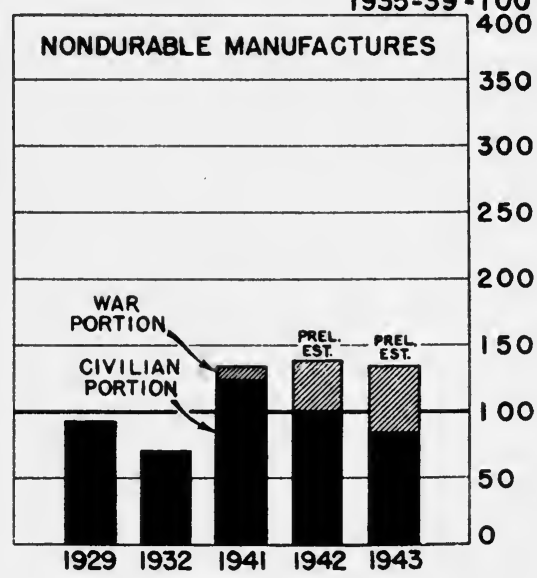




\title{
APPENDIX B
}

\author{
Exhibit I
}

\section{TYPES OF HATCHING AND SUGGESTED CHOICES FOR VARYING NUMBER OF COMPONENT PARTS}

\section{Hatching Done with a Ruling Pen}

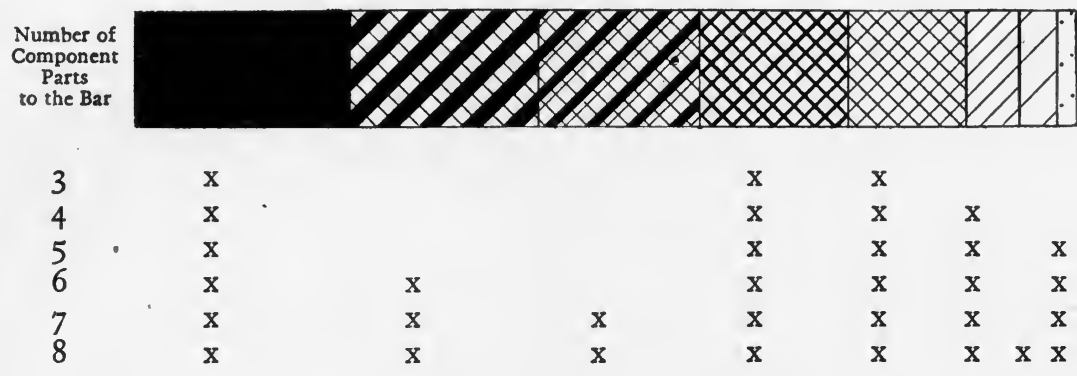

2. Zip-a-Tone, Prefabricated Hatching

\begin{tabular}{|c|c|c|c|c|c|c|c|}
\hline $\begin{array}{l}\text { Number of } \\
\text { Component } \\
\text { Parts } \\
\text { to the Bar }\end{array}$ & & & & & & & 8 \\
\hline & $\begin{array}{c}\text { Zip-a-Tone Order\# } \\
\text { 7-R, }\end{array}$ & 177-R, & 144-R, & 64, & 91, & 51, & 74,22 \\
\hline 3 & $\mathrm{x}$ & & $\mathrm{x}$ & & & $\mathrm{x}$ & \\
\hline 4 & $\mathrm{x}$ & & $\mathrm{x}$ & $\mathrm{x}$ & & $\mathbf{x}$ & \\
\hline 5 & $\mathrm{x}$ & & $\mathbf{x}$ & $\mathbf{x}$ & & $\mathrm{x}$ & \\
\hline 6 & $\mathrm{x}$ & $\mathrm{x}$ & $\mathrm{x}$ & $\mathbf{x}$ & & $\mathbf{x}$ & $\mathbf{X}$ \\
\hline 7 & $\mathrm{x}$ & $\mathbf{x}$ & $\mathbf{x}$ & $\mathrm{x}$ & & $\mathbf{x}$ & $\mathrm{x} x$ \\
\hline 8 & $\mathbf{x}$ & $\mathbf{x}$ & $\mathbf{x}$ & $\mathrm{x}$ & $\mathrm{x}$ & $\mathbf{x}$ & $\mathbf{x}$ \\
\hline
\end{tabular}

Notz: Zip-a-Tone is a prefabricated hatch. It is cut to the proper size from a $10^{\prime \prime}$ by $12^{\prime \prime}$ sheet and rubbed onto the drawing thereby becoming glued to the drawing. The use of Zip-a-Tone eliminates the necessity of hand hatching. Much time and wear and tear on the draftsman can be saved by the use of this prefabricated hatching. Also, neater results are obtained because of the uniformity of pattern. Zip-a-Tone is the trade name of only one type of prefabricated hatching. Other commercial types of hatching can be bought. See the hatching on Charts 18, 19, and 26 for examples of the use of Zip-a-Tone. 


\section{INDEX}

Page

Bar charts................ I0-29

Absolute simple horizontal.........14-1 8 general chart rules, section I..... 6-9 bar arrangement............ I6 bar spacing............... I4 grid $\ldots \ldots \ldots \ldots \ldots \ldots \ldots \ldots$ I 4 line of reference............. I4 scale description............ I 4 scale numerals............... I 4

Bilateral horizontal bar chart........ I 8 Many-item horizontal bar chart...... I6 Absolute simple vertical.......... 10-13 general chart rules, section I..... 6-9 bar arrangement............. 12 bar spacing............... Io grid..$\ldots \ldots \ldots \ldots \ldots \ldots$ ro line of reference.............. Io scale description............. Io scale numerals.............. ro

Component horizontal . . . . . . . 24-29 general chart rules, section I..... 6-9 bar arrangement............. 24 bar spacing............... 24 classification designation........ 24 hatching ................. 25 key ..................... 25 line of reference............ 24 order of component parts........ 25 scale description............. 24 scale numerals............. 24

Absolute component horizontal bar chart ..................26

One hundred per cent component horizontal bar chart......... 28

Component vertical............ 19-23 general chart rules, section I..... 6-9 bar arrangement............ 20 bar spacing.............. I9 hatching $\ldots \ldots \ldots \ldots \ldots \ldots \ldots 20$ key ..................... 20 line of reference............ I9 order of component parts.......20 scale description............ I9 scale numerals.............. I9

Absolute component vertical bar chart. 20 One hundred per cent component vertical bar chart............ 22

Pictorial .................... 50

Three-dimensional ............ 44 Bar description (designation)...5, 7, 14, 24 Business-statistical data, graph of..... 6-9 bar designation.............. 7 curve label................. 7 explanatory note............ 9 field ................. 7 footnote Page

grid $\ldots \ldots \ldots \ldots \ldots \ldots \ldots \ldots \ldots, 7$

key $\ldots \ldots \ldots \ldots \ldots \ldots \ldots \ldots \ldots$. 8

prefatory note............. 7

qualitative classification......... 7

scale description............. 7

scale numerals............. 7

source $\ldots \ldots \ldots \ldots \ldots \ldots \ldots \ldots$. 9

title .................. 6

Curve labels..........5, 7, 36, 38, 42

Curve lines................. 34

Explanatory note............. 5 , 9

Field .................. 5,7

Footnote $\ldots \ldots \ldots \ldots \ldots \ldots \ldots \ldots, 8$

Function of charts............. 3

Grid (scale lines)............... 7

See rule for type of chart desired.

Guide lines............. 22, 28 Hatching $\ldots \ldots \ldots \ldots \ldots . . \ldots 20,25,32,83$ Key ....... 8, 20, 25, 32, 44, 46, 52 Lettering .................. 6, 6-9 Line diagram charts...............34-43 general chart rules, section I..... 6-9 curve label................. 36 curve lines................. 34

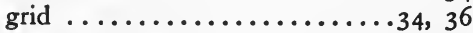
scale description.............. 34 scale numerals.............. 34 Absolute (arithmetic) line-diagram

charts ..................36-38 curve label................. 36 line of reference............. 36 scale numerals.............. 36 uses of ................... 36

Logarithmic line-diagram charts...42-43 curve label................ 42

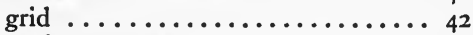
prefatory note.............. 42 scale numerals.............. 42 uses of ................. 42

Percentage (arithmetic) line-diagram charts $\ldots \ldots \ldots \ldots \ldots \ldots \ldots 3^{8-41}$ curve label................... $3^{8}$ line of reference............. 38 scale numerals.............. 38 uses of ................... 38

Line of reference. See rule for type of chart desired.

Log charts. See line-diagram charts.

Maps ..................... 52-53 general chart rules, section I..... 6-9 specific rules.............. 52

Pictorial charts.............. 48-5I general chart rules, section I..... 6-9 specific rules.............. 48 
dangers of.................48

Pictorial bar charts............ 50

Pictorial line-diagram charts....... 5 I

Pictorial pie-diagram charts........ 48

Pie-diagram charts, component......30-33 general chart rules, section I..... 6-9 specific rules................. 32

Three-dimensional . ............4 46

Prefatory note $. \ldots \ldots \ldots \ldots \ldots \ldots, 7,42$

Qualitative classification...........5, 7

Section III, Simple horizontal bar charts ................ I4

Section $\mathrm{V}$, component horizontal bar charts .................24

Section VI, pie-diagram charts...... 30

Section VIII, three-dimensional charts. 44

Quantitative classification

Section II, simple vertical bar charts. . Io

Section IV, component vertical bar charts ................. I9

Section VI, pie-diagram charts...... 30

Section VIII, three-dimensional charts. 44

Scale description (designation)......5, 7 See rule for type of chart desired.

Scale lines (grid lines)........... 7 See rule for type of chart desired.
Scale numerals................. 7 See rule for type of chart desired.

Source ................... 9

Statistical-business data, graph of..... 6-9

bar designation.............. 7

curve label................ 7

explanatory note............ 9

field .................. 7

footnote ................ 8

grid $\ldots \ldots \ldots \ldots \ldots \ldots \ldots \ldots \ldots$

key $\ldots \ldots \ldots \ldots \ldots \ldots \ldots \ldots \ldots, 8$

prefatory note............ 7

qualitative classification........ 7

scale description............. 7

scale numerals............. 7

source $\ldots \ldots \ldots \ldots \ldots \ldots \ldots \ldots, 9$

title ................... 6

Three-dimensional charts. .........44-47 general chart rules, section I. .... 6-9 specific rules............44, 46

Time series

Section II, simple vertical bar charts.. Io

Section IV, component vertical bar charts ................. I9

Section VII, line-diagram charts..... 34 Title .................... 6, 6 


\section{PUBLICATIONS OF THE BUREAU OF BUSINESS RESEARCH}

Wholesale Grocery StUdies

Operating Results of Ohio Wholesale Grocers......................\$0.50

Year 1923, X-3; Year 1925, X-9; Year 1926, X-12; Year 1927, X-21; Year 1928,

X-25; Year 1929, X-30; Year 1930, X-34; Year 1931, X-39; Year 1932, X-45;

Year 1933, X-49; Year 1934, X-50

R- I Salesforce Compensation in Wholesale Groceries $(1924) \ldots \ldots \ldots \ldots \ldots . .$.

\section{Department Store Studies}

R-29 Retail Credit-Office Expense in Ohio Department Stores.............. .50

$\mathrm{X}$ - 6 Sales, Outstandings, and Advertising of Ohio Retail Dry Goods Dealers,

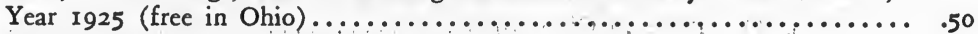

X-13 Merchandise Returns in Department Stores, Sections I and II .......... 2.00 Section I-Reason for Returns............................. 1.00

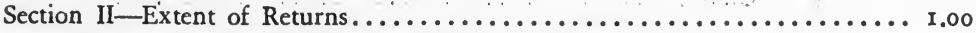

X-18 Administration of Personnel Functions in Ohio Department Stores....... .50

$\mathrm{X}-27$ The Cost of Handling Merchandise Returns (Complimentary with purchase of Merchandise Returns in Department Stores) .................. .25

X-36 The Reasons for and Extent of Markdowns in Ohio Department Stores..... 2.00

$\mathrm{X}-38$ Service Items in Department and Furniture Stores............... .50

\section{Men's Clothing Store Studies}

$\mathrm{X}$-Io Influence of Ten-payment-plan on Prestige of Stores (Complimentary with

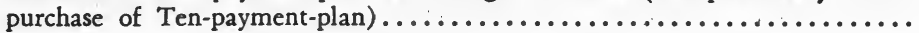

\section{FURNITURE StORE STUdies}

R- 2 A Uniform System of Accounts for Retail Furniture Dealers............ I.00

R- 4 Saleforce Compensation and Expense in Retail Furniture Stores of the Ohio Valley, Year 1924 (free in Ohio) .......................... .50

R-I 4 Installment Credit in the Retail Furniture Trade................ .50

R-I7 Operating Results of Thirty Installment Retail Furniture Stores-1928.... '.50

\section{General Marketing Studies}

R- 3 Housewives' Buying Habits in Columbus, Ohio, Year 1924 (free in Ohio)... . .50

R- 9 The Social and Economic Relations of the Farmers with the Towns in Pick-

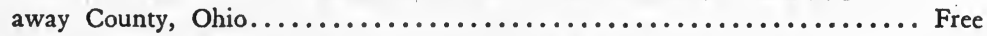

R-12 Ohio Ordinances Regulating Retail Competitive Practices (free in Ohio)..... .50

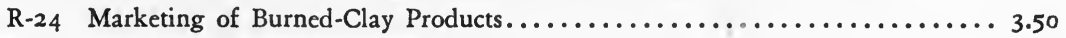

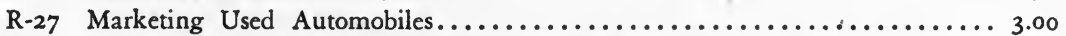

R-30 Factors Affecting Credit Ratings of Consumers in Franklin County, Ohio.... .50

$\mathrm{X}-5$ Content of Advertising Courses in Colleges of Commerce-Agency Suggestions $\quad .50$

$\mathrm{X}-43$ Consumers' Reactions to Special Sales in Columbus Department Stores..... . .50

X-47 Expenditures and Apparel Buying Habits of Ohio State University Students.. .50

Coal Distribuution Studies

R-20 Operating Costs of Retailing Coal in Columbus-r929............. .50

$\mathrm{X}-44$ Distribution and Use of Bituminous Coal in Columbus, Ohio........... .50 
HATCHERY STUDIES

R-13 Operating Expenses in Ohio Accredited Hatcheries-1927........... .25

R-16 Record-Keeping System for Commercial Hatcheries.............. 5.00

X-33 Operating Results of Some Ohio Hatcheries-r930 (free in Ohio)....... ${ }_{.50}$

\section{NewSPAPER StUdies}

R-II Analysis of Revenues and Expenses of Ohio Daily Newspapers.......... .50

R-2I The Facilities of Ohio Newspapers for Retail Advertising............ .50

$\mathrm{X}-\mathrm{II}$ Location, Circulation and Rates of Ohio Daily Newspapers.......... .50

Banking and Building and Loan Studies

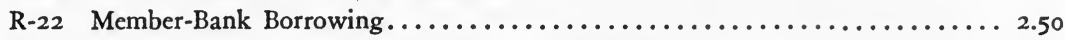

R-23 Ohio Bank Suspensions and Liquidations, $1920-1937 \ldots \ldots \ldots \ldots \ldots \ldots \ldots . \quad .50$

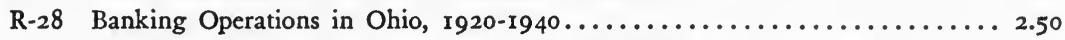

X-19 Historical Balance Sheet Analysis of Ohio Building and Loan Associations

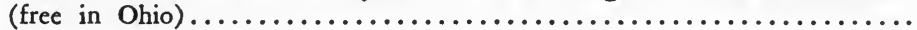

Studies of INDUSTRIes

R- 6 The Construction Industry in Ohio (in Ohio, 50 cents) $\ldots \ldots \ldots \ldots \ldots \ldots$. . . . .

$\mathrm{X}-23$ Industrial and Commercial Ohio, Volumes I and II. The volumes are not

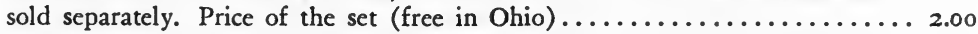

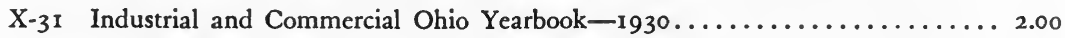

$\mathrm{X}-53$ Ohio: Manufacturing, Trade, Agriculture, Mining-In Graphs.......... 1.00

\section{Industrial Management Studies}

R-15 Study of Content and Arrangement of Employee Magazines-"Plant Organs" .50

R-18 Personnel Practices Among Ohio Industries.................

R-26 The Influence of the Unit of Supervision and the Span of Executive Control on the Economy of Line Organization Structure................ .50

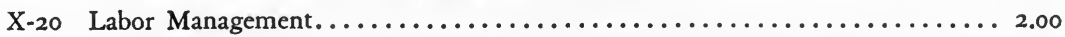

X-26 Material Control and Storeskeeping in Foundries and Machine Shops....... r.50

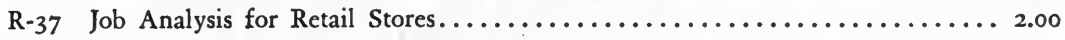

\section{EMPLOYMENT STUDIES}

R- 7 Ohio Employment Studies............................

R-32 Seasonality of Employment in Ohio................................

R-33 Unemployment Compensation Experience of Beneficiaries in Columbus, Ohio

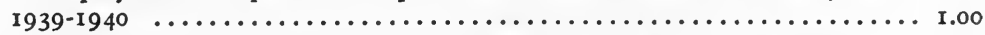

R-34 Effectiveness of Unemployment Benefits in Maintaining Purchasing Power.... 1.00

R-35 Planned Dovetailing of Seasonal Employment..................... 1.o

$\mathrm{X}-40$ A Study of the Labor Turnover in Fourteen Ohio Business Concerns in Relation to Cost of a Hypothetical System of Unemployment Benefits......... .50

$\mathrm{X}-48$ Employment and Pay Roll Fluctuations in Ohio, 1926-1932.......... .50

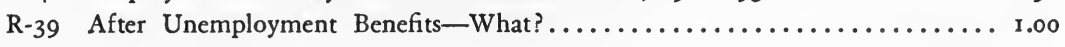

\section{Foreign Trade Studies}

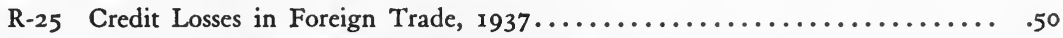

R-36 Postwar Foreign Trade Employment and Sales Prospects in Ohio......... .75

$\mathrm{X}-24$ Credit Losses in Foreign Trade (free in Ohio) ................. .50

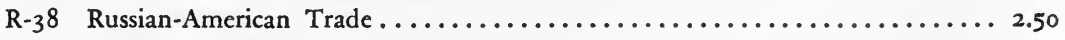




\section{Population Studies}

each

X-4I Population Characteristics by Census Tracts, Columbus, Ohio-1930...... 2.00

X-52 Population Characteristics by Census Tracts, Cincinnati, Ohio-I930 and 1935. I.25

X-54 Columbus: Street Directory for 1940 Census Tracts.................. 1.00

R-43 Census Tract Street Directory for Columbus, Ohio, $1946 \ldots \ldots \ldots \ldots \ldots$ I.50

\section{Real Estate Studies}

X-55 Building Permits-Trends and Distribution, Cincinnati, Ohio, 1908-1938... 1.00

$\mathrm{X}-56$ Real Estate Transactions in Franklin County, Ohio, I9I7, 1937........ 2.00

\section{Miscellaneous Studies}

R-I9 Salaries and the Cost of Living in Twenty-seven State Universities and Colleges-19r3-r932 ............................... 1.75

X-15 A Critical Analysis of the Bankruptcy Law in Ohio (free in Ohio)........ . .50

$\mathrm{X}-28$ Simplified Procedure in the Statistical Analysis of Time Series.......... . .50

$\mathrm{X}-29$ Insurance Trade Press Advertising (free in Ohio) ................ .50

$\mathrm{X}-32$ Attitude of Employers Towards the Ohio Compulsory Education and Child

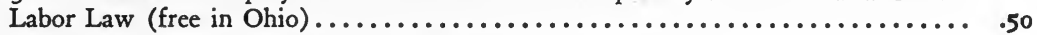

$\mathrm{X}-42$ The Operation of the Ohio Wage Garnishment Law............. . .50

\section{Small Business Handbooks}

B- I Operating a Retail or Service Business in Ohio According to Law.......... I.00

B- 2 Operating a Manufacturing or Wholesaling Business in Ohio According to Law 1.00

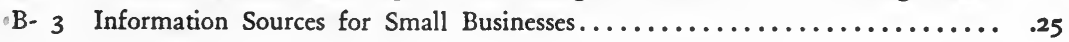

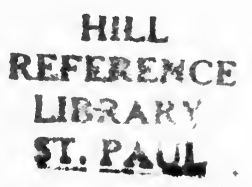








$$
\text { : }
$$



